Article

\title{
The Capital Budgeting of Corporate Social Responsibility
}

\author{
Maria-Teresa Bosch-Badia ${ }^{1}$, Joan Montllor-Serrats ${ }^{2, * \mathbb{C}}$ and Maria-Antonia Tarrazon-Rodon ${ }^{2}$ \\ 1 Deparment of Busines, Universitat de Girona, Campus de Montilivi, 17071 Girona, Spain; \\ MariaTeresa.Bosch@udg.edu \\ 2 Department of Business, Universitat Autonoma de Barcelona, 08193 Cerdanyola del Valles, Spain; \\ MariaAntonia.Tarrazon@uab.cat \\ * Correspondence: Joan.Montllor@uab.cat; Tel.: +34-93-581-1269
}

Received: 23 February 2020; Accepted: 19 April 2020; Published: 26 April 2020

\begin{abstract}
This paper focuses on the evaluation of Corporate Social Responsibility (CSR) investment projects from the perspective of the triple bottom line. One of the most relevant roles of CSR is the mitigation of the negative externalities generated by corporate investments, which often requires undertaking specific investment projects that fall in the scope of CSR. The main goal of these CSR projects is to improve corporate sustainability instead of maximising financial value creation. Thus, they must be evaluated for their impact on the natural, social, and financial capitals, answering these three questions: What is its efficacy for the mitigation of the externalities under consideration? What is its economic efficiency for stakeholders? What is its financial sustainability? The proposed evaluation method interlinks monetary with physical units by generating dimensionless indicators. The paper also presents a metric that unites in a single indicator the effects on the natural, social, and financial capitals. Reliable capital budgeting decisions must fit with corporate strategic planning. Since this principle also holds for CSR, the paper includes a section on the strategic planning of CSR. A numerical illustration and a case study, developed with the aid of text mining techniques, show the applicability of the findings of this paper.
\end{abstract}

Keywords: CSR; capital budgeting; sustainability metrics; value creation

\section{Introduction}

Environmental and social sustainability have become the core components of Corporate Social Responsibility (CSR). Supra-governmental initiatives, mainly the Sustainability Development Goals (SDGs), and social claims have led to acknowledgement of the central importance of CSR for sustainability and, also, to the incorporation of CSR into corporate strategies. As a logical outcome of this tendency, CSR courses of action are increasingly designed with long-term horizons in mind and related to the socio-environmental consequences of corporate investment projects. Essentially, corporate sustainability requires that corporate investment projects add environmental and social sustainability to their financial value creation capacity. Thus, the analysis of corporate projects faces the challenge of evaluating their environmental and social weak points and, afterwards, designing and implementing the appropriate courses of action for their mitigation. The cost-benefit analysis enables managers to realise the negative externalities associated with investment projects. The analysis of the courses of action aimed at controlling or mitigating negative externalities is often best performed by separating it from the study of the leading projects, once their externalities are known. A substantial reason for this independent approach is the fact that several alternative courses of action can be designed for managing the externalities under analysis. We will call these mitigating courses of action CSR investment projects. 
This paper holds that CSR projects need specific strategic planning and capital budgeting analysis. Three central features differentiate them from mainstream projects:

(1) An analysis of their efficacy in natural or social units is central for evaluating their capacity for achieving the goal of mitigating the externalities under consideration.

(2) Their economic impact on corporate stakeholders must be evaluated.

(3) The financial sustainability of the corporation is also a central part of their study.

Thus, assessing CSR investment projects requires the evaluation of these three features from an integrative perspective. They mirror the fact that the goal of CSR projects is to create sustainability and not financial value. Thus, the financial impact becomes a constraint instead of a goal. Namely, the project must be financially sustainable, but the focus on maximising financial value is logically discarded. It is worth pointing out that the financial value of CSR projects comes not only from cash-flow generation but also, and often mainly, from their contributions to reducing corporate risk and improving corporate reputation.

As shown in Section 2, relevant literature exists on the independent evaluation of efficacy, efficiency, and financial sustainability. However, few integrative approaches have been developed. Besides, the analysis of CSR projects cannot stop at the evaluation stage. Their integration into corporate strategy also requires examining them from the perspective of strategic planning. To contribute to filling this gap is the aim of our paper.

Since capital budgeting is a technique, this paper does not aim to test any hypothesis. Instead, its goal is to enlarge a technique, capital budgeting, by building up a model able to unite the analysis of efficacy, efficiency, and financial sustainability in a single framework departing from the existing literature. The research assumptions for this model are the need to include the evaluation of the technical efficacy, economic efficiency for stakeholders, and financial sustainability in the capital budgeting analysis of CSR projects, and the integration of CSR capital budgeting into strategic planning.

On this basis, the paper is organised as follows. Section 2 presents a literature review on the identification of negative corporate externalities and the evaluation of CSR initiatives. Section 3 centres on the strategic planning of CSR projects, underlining the relevance of the links between strategic planning and capital budgeting. Section 4 analyses the sequence of steps of the capital budgeting of CSR. Section 5 studies the metrics of CSR capital budgeting, including the analysis of efficacy, the evaluation of economic efficiency for stakeholders, and the financial sustainability for shareholders. Section 6 presents a numerical illustration and a case study. Section 7 concludes the paper with a discussion.

\section{Literature Review}

This section centres on how the existing literature supports the approach to CSR from the perspective of the mitigation of negative externalities, and on the available metrics for the CSR courses of action. Specifically, it deals with the following topics: (a) the links between CSR, externalities, and cost-benefit analysis (CBA), (b) the environmental and social indicators that measure the impacts of production processes, (c) the indicators of economic efficiency of the social courses of action, and (d) the aggregated metrics that aim to embed the outcomes of multiple measures in a single indicator.

The relationship between CSR and CBA becomes clear when compensating society and stakeholders for the harms generated by corporate activities is assumed as a central goal of CSR. Sheehy [1] (p. 643), examining the evolution of the concept of CSR, points out that "understanding CSR as international self-regulation of harms and public good is a significant step forward". In economic terms, harms and public good can be assimilated to negative and positive externalities. Boardman [2] and Boardman et al. [3] (p. 23) hold that CBA is the instrument through which corporations should measure their CSR. Jenkins et al. [4] apply CBA to the evaluation of the impacts of corporate investment projects on stakeholders by performing a distributional analysis of their externalities. KPMG [5], in its analysis of corporate value, stresses the need for valuing corporate externalities due to the continuous 
pressure for their internalisation. This consultancy has coined the term "age of internalisation" for designing current times. According to this approach, the true corporate value consists of the addition of the corporate value for shareholders and debtholders plus externalities. Porter et al. [6] advocate centring corporate strategy on shared value by directing corporate sustainability towards the creation of value for both society and corporate shareholders. These authors point out that innovation, enhancing productivity, and improving the business environment are the main positive consequences of shared value orientation. By their own nature, shared value projects aim to generate positive externalities and to reduce existing social and environmental externalities. The fact that any well-grounded shared value project is socially responsible is unquestionable. However, even shared value projects may generate negative externalities that could lead corporations to develop specific courses of action, i.e., CSR projects, for their control.

Székely and Knirsch [7] study and compare the economic, environmental, and social indicators applied by twenty major German corporations in the performance analysis of their CSR initiatives. These authors focus on how the chosen indicators contribute to linking CSR with corporate strategy. Singh et al. [8] provide a systematic review of sustainability assessment methodologies. In a similar line, Angelakoglou and Gaidajis [9] examine the available methods for the assessment of environmental sustainability, pointing out the strengths and limitations of each indicator. They review sets of individual indicators (such as the Sustainable Reporting Guidelines, GRI), socially responsible investment indices (as the Dow Jones Sustainability Index, DJSI), composite indices (as the Composite Performance Index, CSPI), material and energy flows (as the Ecological Footprint, EF), environmental accounting approaches, and life cycle analyses (as the Carbon Footprint, CF). Not surprisingly, the complexity of the production processes and the idiosyncrasy of different industries often require building up specific indicators centred on the specific features of these processes and industries. Four examples of this nature are the papers by Singh et al. [10], who present a sustainability index for the steel industry, Naidu et al. [11], focusing on nanoparticle manufacturing processes, Ellison and Brown [12], developing indicators for commercial real estate, and Kouadio and Newlands [13], studying sustainability metrics for agriculture. The indicators included in the rules for CSR reporting issued by several organisations can also be applied to the ex-ante long-term analysis of CSR projects, i.e., to their capital budgeting, although their central focus is ex-post reporting in the short run. Bhattacharya and Cummings [14] develop a model for the evaluation of Corporate Environmental Performance (CEP) that combines environmental managerial performance (EMP) with environmental operational performance (EOP), concluding that CEP depends on these two dimensions (EMP and EOP), which, in turn, are interdependent. In the field of social indicators, Mitnic [15] studies the metrics of corporate social performance (CSP), distinguishing three levels: performance measurement, performance perception, and belief. Salazar et al. [16] propose to measure CSP through social projects. Wood [17] reviews the existing literature on CSP, including its links with CSR. The Global Reporting Initiative (GRI) has created a reporting framework for CSR that issues a set of standards for normalising corporate disclosure on economic, environmental, and social sustainability. GRI standards are thought to match the UN Guiding Principles on Business and Human Rights [18] and concordant principles of other intergovernmental organisations. In brief, GRI turns the essence of these principles into a set of indicators. The Sustainability Accounting Standards Board (SASB) publishes industry-specific standards compatible with the GRI. For each topic (for instance, Greenhouse Gas Emissions, Labour Practices, Competitive Behaviour, and Accident \& Safety Management for airlines), SASB proposes an accounting metric and a unit of measure. Accounting metrics are classified into "quantitative" and "discussion and analysis". ISO has issued standards for specific industries linking them to the SDGs [19]. Chandler [20] (pp. 192-193) lists the leading organisations that have issued rules in this line.

The Social Return on Investments (SROI) is the most usual metric for the estimation of social value creation, expressed, in this case, as a ratio. In practice, SROI is indistinctively used for natural and social capitals. Launched in 1996 by the Roberts Foundation [21] (p. 3), the SROI has received widespread attention from academics and practitioners. Lingane and Olsen [22] systematise the rules 
for applying SROI. Sones et al. [23] point out the adequacy of SROI as a metric of CSR performance. Maas and Liket [24] apply SROI to the analysis of strategic philanthropy. Lombardo et al. [25] analyse the social impact of sports through SROI. Maier et al. (2014) [26], adopting the perspective of NGOs, explore the strong and weak points of SROI. Nicholls et al. [27] provide a detailed and updated methodology of SROI. Nicholls and Patton [28] develop the Project-Valuation-Pricing (PVP) model for the valuation of social projects. This model divides the process of social value creation into three steps: projection (forecasts and their basis), valuation (cash-flow and discount rate estimation plus the calculation of the present value), and pricing (estimating the price of the project through the interaction between supply and demand). Pattison-Williams et al. [29] apply SROI to the analysis of a natural capital project. Secco et al. [30] also consider SROI in the evaluation of forest projects. Bottero et al. [31] develop through SROI a case study on rural development, combining economic, social, environmental, and cultural aspects. To clarify the approach of this paper to the stakeholders' position, let us point out that the impact of a CSR project on stakeholders has two dimensions: their social welfare and their economic welfare. The former comes from the direct effect of the mitigation of externalities, while the latter comes from the economic effects on stakeholders generated by this course of action.

Single metric indicators synthesise environmental, social, and economic performances in a unique index. Sikdar [32] builds up an aggregate metric, based on the geometric mean, able to integrate an unlimited number of specific metrics expressed as dimensionless ratios. Sikdar et al. [33] enlarge this measure. Brandi et al. [34] develop a model based on the Canberra metrics that attributes equal weights to economic, social, and environmental indicators. El-Halwagi [35] presents an indicator that unites investment and sustainability returns. Sikdar et al. [36] display a panoramic view of the available algorithms for generating aggregate indices. West [37] builds up a data envelopment analysis (DEA) model that integrates financial returns, environmental impacts, and social effects in a single index. Wilhelm [38] has developed the Return on Sustainability (ROS) metrics, that generate a single indicator for each CSR course of action after weighing four categories: financial, brand, sustainability, and ease of implementation. The brand category includes an outer side related to customers, stakeholders, and competitors, and an inner side centred on employees. Buffet and Eimicke [39] propose the Impact Rate of Return (iRR) as an indicator that unites the natural and monetary units of impacts' effect.

\section{Strategic Planning vs Capital Budgeting in CSR}

CSR projects reach coherence when they become part of the CSR strategy, which, in turn, must be part of the corporate strategy for gaining competitive advantage [40] and contributing to corporate financial performance. However, the association between CSR, competitive advantage, and financial performance is not automatic. Kim et al. [41] find that CSR improves the financial performance of firms with high competitive-action level, while firms with low competitive-action level benefit from negative CSR. Lins et al. [42] show that high-CSR firms experienced better financial performance during the 2008-2009 crisis than firms that did not excel in CSR. Wang et al. [43], applying a meta-analysis, conclude that there is positive evidence of a causal relationship between CSR and financial performance, being stronger in advanced than in developing economies. The classical meta-analysis by Orlitzky et al. [44] also identified a positive relationship between CSR and financial performance. Despite this evidence, this paper does not assume that corporations will systematically undertake CSR projects. Instead, its scope its limited to firms that decide to study the feasibility of specific CSR projects aimed at mitigating corporate externalities.

The close connection between capital budgeting and strategic planning is a recurrent topic in corporate finance literature. Myers [45] stresses the need for reconciling financial theory and strategic planning, signalling the central role of real options in this respect. In the same topic, Rizzi [46] (p. 84) concludes that "Major strategic decisions can only be resolved by a market based strategic analysis linking investment decisions to the firm's overall market strategy". Capital budgeting focuses on the detailed study of investment projects. Strategic planning places these projects in the framework of corporate strategy. Actually, strategic planning is an outcome of the corporate strategy formulation. By 
studying the different scenarios that it may face, the corporation becomes aware of the opportunities and threats embedded in its environment, and also of its strengths and weaknesses. Next, the corporation focuses on shaping the best courses of action for reaching its strategic goals in the framework of the existing scenarios. Namely, it develops its strategic planning. Capital budgeting, in contrast, departs from the conception of specific investment projects and concentrates on studying their capacity for value creation. However, the value created by investment projects depends not only on their specific features but also on their contribution to corporate strategy. Brealey, Myers, and Allen [47] (p. 270), following [45], underline the complementarity between capital budgeting and strategic planning by pointing out that capital budgeting adopts the bottom-up corporate point of view, while strategic planning adopts the top-down one. Myers [45] and Lai and Trigeorgis [48] highlight the central role of real options in clarifying the links between capital budgeting and strategic planning.

A central point of the connection between capital budgeting and strategic planning is the internal dialogue generated by discussing the features and expectations of corporate investment projects between the top management and the managers of the operating units who deal directly with the projects. This dialogue generates the synergy that springs from uniting the bottom-up and top-down approaches signalled by Brealey, Myers, and Allen [47] (p. 270), who insist on the fact that an investment project is the outcome of a negotiation inside the corporation between managers with different positions and functions. Desouza et al. [49] and Ciriello and Richter [50], among others, have studied the value of employees' thinking to foster innovation. In the framework of corporate exchanges on strategic and investment project decisions, capital budgeting adds the rigour of numerical figures and structured quantitative methods to the qualitative designs of pure strategical approaches. At the same time, qualitative approaches provide the conceptual framework that makes it possible to identify and classify the available courses of action for facing corporate challenges. Paraphrasing Schoemaker [51] and Amram and Kulatilaka [52], capital budgeting contributes to discipline corporate decisions in line with scenario planning and real options analysis. These considerations on the links between capital budgeting and strategic planning lead to two conclusions. First, capital budgeting must be integrated into strategic planning. Second, corporate dialogue is essential in the corporate value creation process that emerges from uniting the bottom-up level of capital budgeting with the top-down level of strategic planning.

In the field of CSR, the coordination between capital budgeting and strategic planning is even more essential for any corporation that attempts to develop a strategic CSR. In this case, strategic CSR, far from being a conglomerate of different initiatives, follows a coherent line integrated into the mainstream corporate strategy. Let us examine how the link between capital budgeting and strategic planning applies to CSR projects. Cost-benefit analysis constitutes a tool for identifying the weak points of corporate environmental and social sustainability. On this basis, the scenario analysis of CSR focuses on the discovery of corporate actions that may mitigate these negative externalities. The next step consists of structuring these opportunities as CSR projects that will be analysed, in turn, from the points of view of their socio-environmental efficacy, their social-economic efficiency, and their financial sustainability for the corporation. All this analysis is part of the design of the CSR strategy centred on externalities. Accepted CSR projects will then be integrated into the strategic planning of CSR. Throughout this process, the synergy created through corporate dialogue is revived. The interaction between qualitative and quantitative approaches fosters synergy in the same line. Both cost-benefit and capital budgeting analysis of CSR projects protect CSR decisions from wishful thinking. In other words, both approaches discipline CSR decisions by evaluating needs and opportunities. Strategic analysis, in turn, becomes central for identifying the possible courses of action that will enable the corporation to mitigate externalities, and for structuring the adopted courses of action coherently. The corporate dialogue raised by the interaction between capital budgeting and strategic planning is even more important in the field of CSR. Now corporate dialogue should be extended to stakeholders. In this respect, Arvidson [53] regards SROI as a valuable tool for structuring the corporate dialogue with stakeholders. Yates and Marra [54] explore the advantages and problems of SROI, including 
stakeholders' motivation, among its advantages and the cost of its estimation as a potential problem. Wilhelm [38] emphasises the relevance of the internal dialogue and, at the same time, talking with stakeholders. Porter and Kramer's shared value [55] assumes corporation-stakeholders dialogue due to its own essence. Porter et al. [6] stress the relevance of putting aside siloed thinking, i.e., avoiding the creation of barriers to information sharing inside the corporation.

All in all, the strategic planning of CSR generates a circle that starts from the general lines of the CSR strategy, once they are harmonised with the mainstream corporate strategy. This is followed by the scenario analysis, grounded in the outcomes of cost-benefit studies. The identification of the different scenarios provides the basis for starting a dialogue with employees and stakeholders to realise their socio-environmental points of view and demands. The addition of the corporate scenario analysis for CSR with the stakeholders' contributions gives birth to shared scenarios that are crucial for well-grounded CSR and shared value. An accurate study of these scenarios enables the corporation to revise its CSR strategy and to make it concrete in the context of CSR strategic planning. A logical outcome of this process is the design of the top-down CSR investment projects, i.e., the ones that have their origin in the strategic planning. Corporate unities may also contribute by generating CSR projects based on their points of view and experience, i.e., bottom-up projects. Both types of projects are analysed through capital budgeting techniques, although from the specific approach that CSR requires, namely from the triple perspective of natural, social, and financial capitals. The projects that are positively evaluated through capital budgeting are then re-examined for evaluating their compatibility with the CSR strategy, to build up a coherent portfolio of projects. In brief, the strategic planning of CSR shows the complexity of combining natural, social, and financial capitals in the design of CSR strategies. The capital budgeting of CSR must provide a method for articulating this complexity with two goals in mind: first, identifying the logical steps of the evaluation process, and second, proposing appropriate metrics for quantifying the impacts of each step. Sections 4 and 5 , respectively, deal with these topics.

\section{The Capital Budgeting Circle}

The first approach to an investment project that a corporation considers undertaking consists of its analysis through capital budgeting techniques focused on financial value creation. The central goal of this analysis is to estimate the project's impact on the corporate value in the financial market. However, for any corporation that aims to implement a CSR strategy based on sustainability, analysing investment projects from the perspective of financial value creation is not enough. The first step for linking the project under analysis with sustainability consists of identifying its negative and positive impacts on the natural environment and society. Thus, submitting the project to a cost-benefit analysis becomes compulsory. Then, negative externalities will be revealed. The inclusion of a distributional analysis among stakeholders, in line with Jenkins et al. [4] (pp. 352-383), is especially valuable for this purpose. Obtaining the outputs of this analysis in natural units is strictly necessary as well for future decisions on CSR projects. In the context of this paper, the term "natural units" stands for any non-monetary unit, including the direct measurement of the impacts of environmental and social phenomena.

Once the corporation has identified the project's externalities in natural and monetary units, CSR analysis starts. Positive externalities may be integrated into the marketing strategy. Negative externalities will become the primary concern of CSR. The design of specific new projects for the mitigation, control, and compensation for negative externalities gives way to a new stage of capital budgeting. These projects require a twofold analysis: first, assuming the point of view of stakeholders, and second, adopting the shareholders' perspective. Instead of financial value creation, the primary goal now becomes value creation for the natural and social capitals-in other words, the improvement of the corporate impact on nature and society that counterbalances the negative externalities under analysis. CSR projects may have different relationships with externalities: complete neutralisation, partial neutralisation or mitigation, and undertaking research to find future solutions. The latter can 
be applied to external research directed at improving environmental and social conditions related to externalities. Strategic giving [56], namely philanthropy based on corporate skills, is another possible issue.

Departing from these considerations, the analysis of CSR projects raises three main questions:

(a) What is the efficacy of the project for controlling the externality under consideration?

(b) What is the economic efficiency of its contribution to stakeholders and society?

(c) Is the project financially feasible for the corporation?

The answers to these questions show how making a corporation sustainable through CSR projects generates a capital budgeting circle. This circle starts with the analysis of an ordinary investment project through traditional capital budgeting techniques, and it closes by applying the same techniques to check the financial sustainability of the CSR project aimed at mitigating its externalities. The intermediate steps of this circle comprise the identification of the externalities, the design of a CSR project to control them, and the evaluation of this project from the perspectives of the natural and social capitals. Systematising, the steps of the capital budgeting circle consist of evaluating:

(a) The financial value creation capacity of the mainstream project.

(b) Its externalities, negative and positive.

(c) The financial value creation of the projects that spring from the positive externalities.

(d) The efficacy of the projects aimed at controlling the negative externalities.

(e) The economic efficiency of these projects for the stakeholders.

(f) The financial sustainability for the corporation of the CSR projects.

To study the financial sustainability of a CSR project, the analyst must isolate its impacts on corporate financial value. CSR literature has widely considered the potential positive impacts of responsible courses of action on corporate value. Among them, innovation is paramount, as underlined in the works by Porter and Kramer. Other relevant sources of value creation associated with CSR initiatives are regulatory risk reduction, attracting skilled workers and, at the same time, responsible consumers and investors, increasing corporate reputation, and facilitating marketing campaigns. The impacts of CSR projects on corporate value have a negative and a positive side that is worth approaching separately. The negative side consists of the expenses and investments devoted to the control of externalities. The positive side consists of the set of opportunities signalled above. Often, it is mandatory to analyse these opportunities. Husted [57] relates CSR to risk management through real options. Cassimon et al. [58] extend the Husted model to the timing of CSR investments. Bosch-Badia et al. [59] study the role of real options in CSR from the point of view of financial sustainability. Figure 1 summarises the capital budgeting circle from the point of view of the mitigation of negative externalities. All of these steps require different metrics. The next section focuses on them.

Figure 1 depicts the capital budgeting circle for CSR, showing the additional complexity it involves when compared with standard capital budgeting. The right-hand side of the circle shows the generation of the CSR project. The corporation undertakes an ordinary project, identifies its externalities through CBA and, afterwards, designs a CSR project for their mitigation. The left-hand side of the circle depicts the analysis of the feasibility of the CSR project, which includes its technical efficacy, its economic efficiency for stakeholders, and its financial sustainability.

The features of the capital budgeting circle convey that its analysis must combine different methodological approaches. The differences lie on the units of measurement and the evaluation method. The outcomes of natural and social capitals actions come in natural units, while monetary units replace them when the focus is on economic efficiency or financial sustainability. Discounted cash-flow and, in some cases, real options constitute the appropriate methodology for economic and financial evaluation. The measurement of environmental and social efficacy usually uses technical indicators, or indices when combining different units in a conjoint measure. The next section centres on the metrics for the evaluation of CSR projects. 


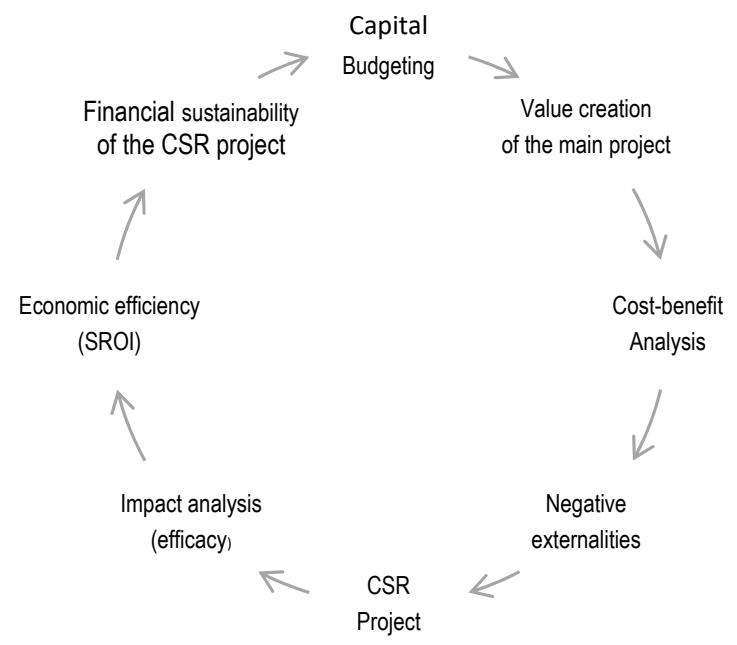

Figure 1. The capital budgeting circle.

\section{Metrics}

Approaching CSR from the perspective of externalities highlights the pertinence of associating CSR projects to any mainstream project that generates externalities. The capital budgeting circle that springs from the interaction between both types of projects requires the use of different metrics at its different stages. This section focuses on the analysis of the most appropriate metrics for each stage. The well-known traditional capital budgeting techniques furnish the appropriate metrics for the financial evaluation of the corporate mainstream projects. Bierman and Smidt [60] and Herbst [61] present a broad perspective of these techniques. Brealey, Myers, and Allen [47] centre their analysis of corporate investments on the net present value (NPV) and pay substantial attention to the practical problems associated with capital budgeting. Magni $[62,63]$ goes beyond the traditional approaches, solving their main drawbacks. Once the financial value creation capacity of a project has been accepted, the study of its externalities through cost-benefit analysis may start. After estimating the counterfactual scenario (i.e., the estimated scenario without the project), the cost-benefit analysis proceeds to identify the project's impacts, quantifying them in natural units first, and in monetary units later. Jenkins et al. [4] present a broad study of the CBA of investment projects. A central output of the cost-benefit analysis is the classification of the different externalities in homogeneous groups. This information constitutes the basis for designing CSR projects focused on the mitigation of negative externalities.

The link between cost-benefit analysis and CSR raises the challenge of selecting the appropriate metrics for the quantification of the different stages of the capital budgeting circle presented in the previous section. Therefore, the analytical study of the capital budgeting circle needs indicators for:

(1) Summarising each group of homogeneous negative externalities in a single measure.

(2) Measuring the efficacy of each CSR project in the mitigation of externalities.

(3) Analysing the economic efficiency of the CSR project for stakeholders.

(4) Analysing its financial sustainability.

\subsection{Summarising Externalities}

The impact measures on natural units need, first, a direct estimation, which is at the same time a necessary step for the applicability of any other metrics. Following the OECD's classification of indicator sets for sustainability manufacturing [64] (pp. 90-145), the first approach consists of choosing a set of individual indicators, defined as the ones that "measure single aspects individually" [64] (p. 100). Selecting the most relevant indicators leads to the next category of this classification, the key performance indicators, defined as "a limited number of indicators for measuring the key aspects that are defined according to the organisational goals" [64] (p. 100). However, in this case, the key aspects are the 
negative externalities the corporation decides to mitigate through CSR projects. Other indicators, such as composite indices and material flow analysis, can be the appropriate choice if they mirror the externalities under study more effectively. Since, at the current stage, the goal is to measure the relevance of externalities in natural units and the efficacy of their mitigation through CSR, indicators based on monetary units are not applicable.

\subsection{Measuring the Efficacy of the CSR Project for the Natural and Social Capitals}

The identification of the groups of homogeneous externalities gives way to the design and evaluation of the CSR projects aimed at mitigating those externalities. Once a CSR project has been designed, the first step in its evaluation consists of studying its efficacy. The basis for this analysis is the externalities indicator that was previously chosen. To this end, we define the efficacy ratio for the natural capital $(\gamma)$ as the quotient between the initial value of the indicator $\left(\varepsilon_{0}\right)$ and its value at the horizon of the analysis $\left(\varepsilon_{h}\right)$, which will be an expected value in the ex-ante analysis:

$$
\gamma=\frac{\varepsilon_{0}}{\varepsilon_{h}}
$$

This ratio expresses the improvement in the natural capital produced by the reduction in its deterioration, achieved by the CSR project. A usual presentation of the natural capital ratios consists of defining them by placing the final value of the indicator in the numerator, and the initial value in the denominator. Then, any reduction denotes an improvement. According to the approach adopted in our paper, any increase expresses an improvement and any reduction a deterioration. In this way, the evolution of the natural capital ratios receives an interpretation in line with the social and financial indicators that systematically associate increases to improvements and decreases to deteriorations. In a multiperiod context, as is usual in investment projects, the impact of CSR on the natural capital can be summarised by the geometric mean of its efficacy ratios in the different periods and the efficacy rate associated to this geometric mean (see Appendix A).

The rate of improvement of the natural capital $(\omega)$, henceforth natural efficacy rate, can be written as:

$$
\varepsilon_{0} e^{-\omega}=\varepsilon_{h}
$$

This paper does not apply discounting rates in the estimation of the present equivalence of the efficacy indicators for the natural capital expressed in natural units because of the lack of a unanimous criterion on this topic. Yet the measures we use can be straightforwardly adapted to weighting the efficacy in different periods, using utility criteria in line with the ones applied in cost-effectiveness studies, most of them focused on Health Economics. However, the discounting rules that drive the present value of cash-flow streams are not valid as a general rule for streams expressed in natural units. Keeler and Cretin [65] discuss this topic. Scrieciu et al. [66] study the methodological complexities of climate change analysis, stressing the need for public and private coordination in this field, which makes this approach relevant for CSR efficacy analysis. Jenkins et al. [4] (pp. 400-417) synthesise the main features of cost-effectiveness analysis.

The social capital indicators present a substantial difference with regard to the natural capital ones. Any improvement in natural capital leads to a reduction of the indicators, because they have been built up by interweaving negative effects of corporate projects on the environment. Conversely, social improvements are reflected by increases in social welfare indicators. Thus, the efficacy ratio of the social capital $(\varsigma)$ can be defined as the quotient between the value of the social indicator at the horizon of the analysis $\left(\theta_{h}\right)$ and its initial value $\left(\theta_{0}\right)$ :

$$
\varsigma=\frac{\theta_{h}}{\theta_{0}}
$$

Naming $\eta$ the efficacy rate of social capital, we have: 


$$
\theta_{0} e^{\eta}=\theta_{h}
$$

In a multiperiod setting, the social impact is summarised through the geometric mean, as in the analysis of the environmental impact.

\subsection{Analysing the Economic Efficiency and Financial Sustainability of CSR Projects}

To measure the economic efficiency for stakeholders and the financial sustainability for shareholders, this paper proposes the SROI and the Present Value Index (PVI), respectively, because their technical similarity facilitates a homogeneous approach to the four indicators required by the capital budgeting of CSR projects. Besides, they can be integrated in a single metric, as shown at the end of this section.

The economic efficiency of a CSR project with respect to its stakeholders has the SROI as its most straightforward metric. As is known, the SROI consists of the ratio between the present value of incremental cash-flows for stakeholders originated by the project (SPV) and the present value of the capital outlays absorbed by it (PVC):

$$
S R O I=\frac{S P V}{P V C}
$$

The value creation capacity for stakeholders embedded in the project, that turns the capital invested (PVC) into stakeholder value, can also be expressed through the stakeholders' value creation rate $(v)$ defined as the rate that expresses the transformation of PVC into SPV:

$$
P V C e^{v}=S P V
$$

Hence:

$$
S R O I=e^{v}
$$

The role of the stakeholders' value creation rate in the framework of this metric is to obtain a measure for stakeholder value that can be compared with the efficacy rates formerly introduced and with the value creation rate for shareholders that we present below. This homogeneity is also necessary for obtaining the overall profitability rate that we deduce at the end of this section.

The Cabinet Office Guide to Social Return on Investment [27] presents a step-by-step approach for calculating SROI. As pointed out by Pathak and Dattani [67], the main technical challenges involved in the calculation of SROI are choosing the appropriate discount rate, allocating overhead costs, and determining the deadweight and displacement cash-flows. A discussion on the discounting rate for the cash-flows associated with the natural and social capitals falls beyond the scope of this paper. On the appropriate discounting rate for environmental projects, the different criteria by Stern [68] and Nordhaus [69] have been the basis of many studies on this topic. Markandya [70] and Markanday et al. [71] provide clear reviews on environmental discounting. Nicholls et al. [28], Marini and Scaramozzino [72], and Maier et al. [26], among others, discuss the appropriate discount rate for the SROI.

Next, we centre on the financial sustainability of the CSR project. Any financially sustainable project creates value for shareholders. The comparison between the present value of the capital invested and the value created for shareholders is provided by PVI, also called profitability index [60] (pp. 144-145). It consists of the ratio between the gross present value (GPV) and the present value of the capital outlays of the project under analysis:

$$
P V I=\frac{G P V}{P V C}
$$

Paralleling the value creation rate for stakeholders, the value creation rate for shareholders can be defined as the rate that expresses the transformation of the capital invested into the gross present value for shareholders: 


$$
e^{f}=\frac{G P V}{P V C}
$$

The close link between $f$ and financial value creation justifies calling it "financial value creation rate". The stakeholders' cash-flows have been discounted at a social discount rate to obtain the SROI. However, financial sustainability depends on the capacity for generating value by competing with ordinary projects. Thus, the cash-flows that stem from the financial value creation opportunities embedded in the CSR project must be discounted by applying ordinary rates. In other words, their required rate of return incorporates a risk premium according to the risk level of this part of the CSR project, centred on financial value creation.

Real options also have a central role in the capital budgeting of CSR. For the model we have presented, their link with the present value is central. The value of real options embedded in cash-flow generating projects (i.e., standard projects) must be added to the NPV of the main project. When the project does not generate a cash-flow stream and consists exclusively of an investment that creates a real option, the profitability index is obtained by substituting the real option value in the numerator of Equation (8) because, in this case, the value of the real option constitutes the entire gross present value (GPV) of the project. Then, the NPV is obtained by subtracting to the value of the real option the amount invested for creating it.

\subsection{The CSR Vector and the Overall Profitability Rate}

All in all, we have presented four ratios that, respectively, express the degree of efficacy for the natural capital $(\gamma)$, its equivalent for the social capital $(\varsigma)$, the degree of economic efficiency for the stakeholders (SROI), and the degree of financial sustainability (PVI). Thus, the outcome of a CSR project can be represented by the vector that contains these four indicators:

$$
\{\gamma, \varsigma, S R O I, P V I\}
$$

Or, alternatively, by their equivalent rates of natural capital efficacy, social capital efficacy, and value creation for stakeholders and shareholders:

$$
\{\omega, \eta, v, f\}
$$

The four indicators of the CSR vector can be united in a single metric following the work by Sikdar [32,33]. The aggregate metric that we propose is an adaptation of Sikdar [32], who proposes the weighted geometric mean for measuring the distance between the initial and the final states of a system. Both states are defined by a set of heterogeneous measures turned into dimentionless ratios. In the Appendix A, we present a detailed development of the rationale for applying Sikdar's metric to the CSR vector. After some mathematical operations, also detailed in the Appendix A, the outcome of applying Sikdar's distance to the CSR vector can be summarised in the weighted arithmetic mean of the rates included in this vector-in other words, as the weighted arithmetic mean of the continuous rates of efficacy and value creation:

$$
\mu=w_{\omega} \omega+w_{\eta} \eta+w_{v} v+w_{f} f
$$

where $w_{\omega}, w_{\eta}, w_{v}$, and $w_{f}$ stand for the corresponding weights. The value of each one of these weights is decided according to the importance that the corporation attributes to each element of the CSR vector, under the obvious condition that its addition must equate 1 . We call $\mu$ the overall profitability rate of the CSR project.

All in all, the capital budgeting of CSR projects requires a multicriteria approach that succeeds in measuring their efficacy for the natural and social capitals, their economic efficiency for stakeholders, and their financial sustainability for shareholders. The measures proposed in this section consist 
of the efficacy ratios for the natural and social capitals, the SROI for stakeholders, and the PVI for shareholders. Turning these indicators into rates of change, we obtain the percentages in which the project improves the natural capital and the social capital and transforms the monetary invested capital into value for stakeholders and shareholders. The whole set of these indicators constitutes the CSR vector. By applying a transformation of Sikdar's geometric mean metric, the four indicators can be encapsulated in a single measure. From the methodological point of view, the questions and answers that appear in the analysis of the capital budgeting of CSR require interweaving of a substantial volume of concepts. Table 1 summarises them according to the approach developed in this paper. The next section starts with a numerical illustration of the metrics for capital budgeting projects that we have just presented. Figure 2 displays this illustration in a conceptual map that links, through numerical figures, the main formulae of this metric.

Table 1. Questions and answers on the capital budgeting of corporate social responsibility (CSR).

\begin{tabular}{|c|c|}
\hline Questions & Answers \\
\hline What is the goal of a CSR project? & Mitigating corporate externalities. \\
\hline Which economic and financial conditions must it satisfy? & $\begin{array}{l}\text { Be economically efficient for stakeholders and } \\
\text { financially sustainable shareholders. }\end{array}$ \\
\hline How to measure the project's impact on natural and social capitals? & The efficacy ratios for both capitals. \\
\hline What are the inputs for the efficacy ratios? & $\begin{array}{l}\text { Indices based on the externalities under analysis that } \\
\text { summarise the current state of both capitals and their } \\
\text { evolution. }\end{array}$ \\
\hline How to measure the economic efficiency for stakeholders? & Social Return on Investments (SROI). \\
\hline How to measure the financial sustainability for stakeholders? & Present Value Index (PVI). \\
\hline Can these measures be turned into rates of return? & $\begin{array}{l}\text { They can be turned into rates of change that express } \\
\text { the improvements (or deteriorations) in each capital. }\end{array}$ \\
\hline How can we obtain a global view of the whole impacts? & Through the CSR vector. \\
\hline Can the different impacts be summarised in a single metric? & Yes, the overall profitability rate. \\
\hline Can the different impacts on the overall profitability rate be weighted? & Yes, according to the criteria of the decision-maker. \\
\hline
\end{tabular}

\section{Numerical Illustration and Case Study}

\subsection{Numerical Illustration}

This section explores the practical applicability of the analytical part of this article through a numerical illustration and a case study. The numerical illustration is integrated into the conceptual map shown in Figure 2. The conceptual map and numerical illustration aim to summarise the metrics for CSR projects proposed in this paper. To facilitate its reading, it is divided into four matrices (from A to D). The company under analysis has decided to undertake the investment project shown at the top of the figure. This project shows a good value creation potential, but, at the same time, it will generate negative environmental externalities. For the sake of clarity, we assume that these externalities have homogeneous features that, after a technical study, have been summarised in a single index with an initial value of 100 points. Social externalities are supposed to be nil. The company decides to undertake a CSR project to mitigate the externalities of the main project. Its features are presented in three matrices (A, B, and C) that, respectively, summarise the project's technical efficacy (A), its economic effects for stakeholders (B), and its effect on corporate value (C). The discount rate for estimating the SROI has been set up at 3.5\%, following [27]. For the shareholders' project, we apply a discount rate of $11 \%$ by assuming that it embeds the market risk premium adjusted to the beta of the project. The indicators shown in these matrices are explained in Section 5 (Metrics). In this way, CSR projects are approached from the points of view of their three central impacts: technical efficacy, economic efficiency, and financial sustainability. The CSR matrix (D), in which we include the aggregate metrics developed in Section 5, encapsulates the overall impact of the CSR project. 


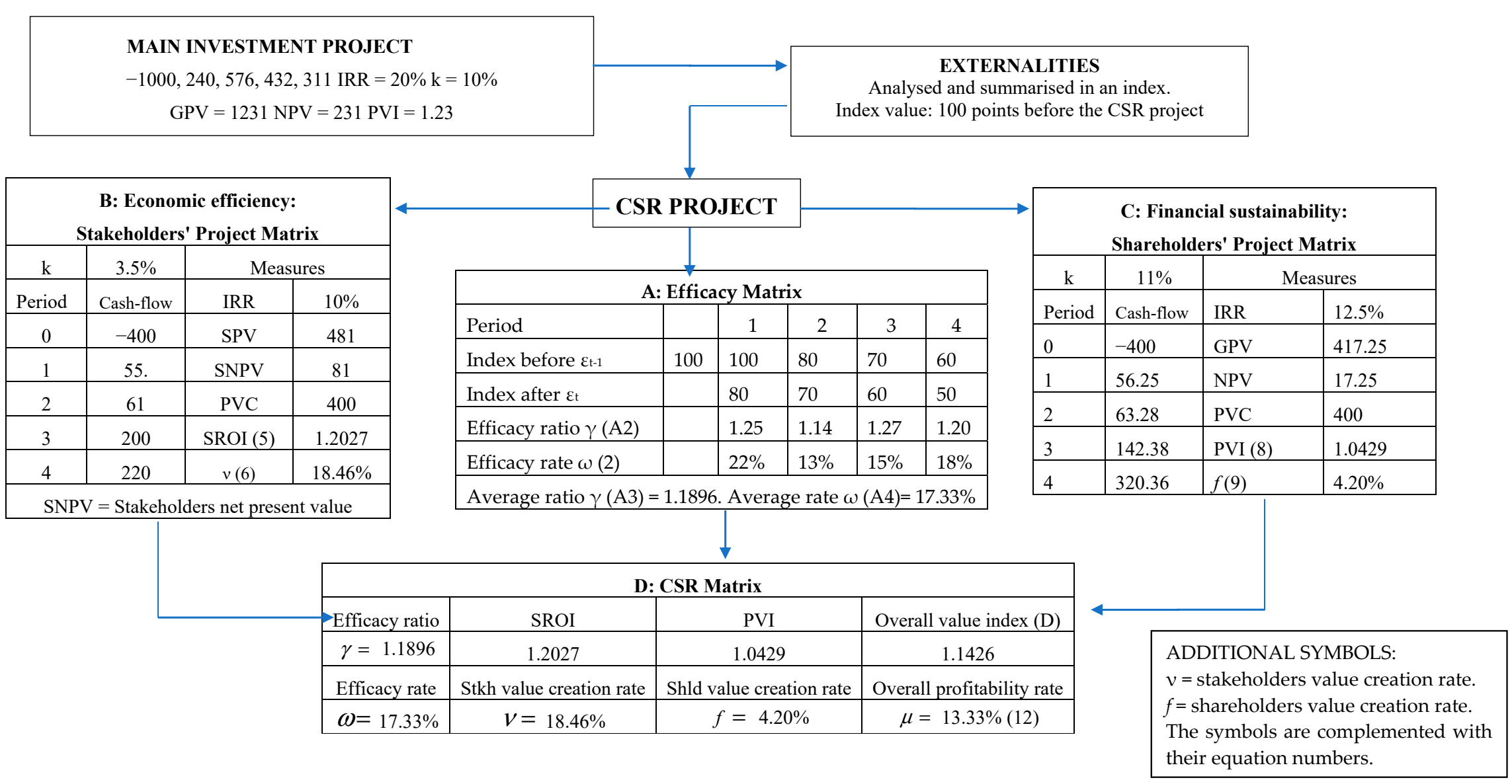

Figure 2. Conceptual map and numerical illustration. 


\subsection{Case Study}

The aim of this case study consists of checking whether the features of the mainstream investment and the CSR policy of the company under analysis are compatible with the approach to CSR adopted in this article. Specifically, this case study aims to answer the following questions:

(a) Is the CSR policy of this corporation focused on mitigating the externalities generated by its mainstream activity?

(b) Does the corporation undertake investment projects for their mitigation?

(c) Does the corporation dialogue with stakeholders on sustainability issues?

(d) Does the corporation aim to create value for stakeholders?

(e) Is its CSR policy also oriented to creating value for shareholders?

A representative company in the field of CSR is the International Airlines Group (IAG). As stated in its sustainability report [73] (p. 53), IAG performed in 2017 a materiality report following the Global Reporting Initiative Sustainability Guidelines, and in 2018 it worked with the Global Reporting Initiative and the Air Transport Association (IATA) in the GRI Sectorial Guidance Handbook for airlines. Its Sustainability Report follows the Directive 2014/95/EU on non-financial reporting and the relevant legislation in the UK and Spain.

This case study focuses on this corporation. The method of analysis consists of a detailed study of the integrated financial and sustainability report of 2018 [73], complemented with the support of a frequency analysis through text mining techniques. Frequency analysis is a well-known technique of text analysis. Archer [74] points out that the relevance of frequencies is due to the fact that the author's choice of words is seldom arbitrary. Davies [75] (p. 68) stresses that frequencies should be considered in context. Ignatow and Mihalcea [76] (p. 84) discuss the value of word clouds for text analysis, praising their contribution to identifying keywords and comparing the word usage across documents and signalling that, when considered alone, they lead researchers to put the context aside. Popping [77] points out the need for systematically submitting the outcomes of quantitative text analysis to qualitative interpretation. Consequently, following the arguments stated by Davies, Ignatow, Mihalcea, and Popping, text mining is used in this case study as a complementary technique for illustrating the conceptual analysis of IAG reports. A remarkable example of text mining application is the text mining handbook for central banks by Bholat et al. [78] for the Bank of England.

Carbon emissions, not surprisingly, are the primary focus of the chairman's letter [73] (p. 53), as well as of the whole sustainability report. Aircrafts noises constitute another externality that receives remarkable attention concerning corporate relations with communities [73] (p. 53) and the corporate commitment to SDGs (p. 60). Waste reduction is mentioned in a similar line [73] (p. 68). IAG has undertaken several investment projects for mitigating carbon emissions, some of them also associated with noise reduction. Investing in the modernisation of the fleet with a $20 \%$ reduction on carbon emissions and a $50 \%$ on noise is one of the most relevant projects. New software for improving fuel efficiency, actions for reducing waste in the aeroplanes, and substituting traditional vehicles for electric ones at airports are other relevant initiatives. Supporting research for cutting down emissions-specifically research projects, as the Futures Fuel challenge, with universities and other partners [73] (p. 55), can be interpreted as a CSR line that generates real options. The corporate dialogue with stakeholders takes place at two levels. First, shared initiatives with industry partners and associations [73] (p. 53) for improving environmental conditions centred on airlines, mainly with fuel efficiency in mind. Second, talking with communities placed near airports with IAG hubs about noise reduction initiatives can be regarded as a way of generating valuable information for the noise reduction projects [73] (p. 53). The former case constitutes an example of generating financial value through business partnerships on sustainability. The corporate dialogue with employees is, logically, more related to labour conditions than with new investments. The corporate interest on social capital is shown by supporting programmes for employees, gender equality actions among them, and external programmes on scholarships for STEM studies that may provide the future workforce for IAG. Finally, 
the link with CSR and corporate value creation is shown by the repeated statements about creating sustainable value. To sum up, the answers to questions (a) to (e) show that the CSR of IAG mainly focuses on the mitigation of corporate externalities and assumes the goals of technical efficacy, social efficiency, and financial value creation in their main courses of action.

The study of word frequencies in IAG reports corroborates these conclusions from the perspective of text mining. IAG discloses its financial and sustainability information in an integrated report. The text analysis starts by exploring the whole sustainability report and, next, it centres on the sustainability chapters. Ignatow and Mihalcea [76] (p. 57), among others, point out that word distribution often follows Zipf's law. However, this is not the case of the text under analysis. Through Mathematica software, we have estimated a value of 0.72 for the coefficient of the Zipf's distribution applied to the frequencies of the Strategy Report. For the Sustainability Report, this value becomes 0.87 . However, the estimation of the distribution fit refutes the hypothesis that the samples of both reports come from a Zipf's population. Turkel [79] presents the complete development of the applicability of Mathematica software to text analysis.

The outcome of this application of text mining consists of the statistical analysis of the list of most frequent words, together with the corresponding bigrams and trigrams. The word clouds illustrate the results. The first step of the text analysis was to eliminate stop-words and homogenising synonymous. The most frequent meaningful words in a text, i.e., excluding stop-words, can be taken as its keywords, after considering them from the perspective of the whole text. The integrated report presents a high concentration of words related to corporate strategy but also sustainability. Table 2 shows the most frequent words, while Tables 3 and 4 display the most frequent bigrams and trigrams, respectively. In the tables that report bigrams and trigrams (Tables 3 and 4 for the strategic report and Table 6 for the sustainability report), we have excluded the outputs that are non-significant for the current analysis by maintaining, of course, the correct position of each bigram and trigram in the frequency ranks. The mean of the frequency is 5 , with a standard deviation of 11 and a skewness coefficient of 11 as well. The frequencies of the twenty most used words range from 65 to 283. The upper quartile starts at a frequency equal to the mean, and the upper $1 \%$ starts at a frequency of 43 . The word cloud in Figure 3 shows a visual image of the word concentration. Figure 4 displays the frequencies concerning the number of words in each position and shows the significant weight of the most frequent words. From these results, we can conclude that the analysis of the whole report shows a corporation concerned with its customers, operations, costs, and financial performance, which fits the goal of value creation for shareholders. The associations that bigrams and trigrams identify, where "chief executive officer" and "management committee" occupy paramount positions, stress the logically important role of corporate leaders in the management of the concerns and challenges reflected in word frequencies. However, words related to sustainability also appear in the most frequent words list, although in a lower position ("sustainability" in the 13th position, "emissions" in 17th, "impact" in 19th, and "carbon" in 20th). Remarkably, "fuel efficiency" turns out to be the 5th bigram, while "climate change" becomes the 22st. The 8th, 13th, and 14th trigrams show the corporate concern with the Sustainability Development Goals, where "link" becomes a keyword, showing that the IAG report relates its CSR to the SDGs.

Table 2. Word frequency in the Strategy Report.

\begin{tabular}{llllll}
\hline Position & Word & Frequency & Position & Word & Frequency \\
\hline 1 & customer & 283 & 11 & fuel & 87 \\
\hline 2 & operations & 253 & 12 & employee & 73 \\
\hline 3 & cost & 185 & 13 & sustainability & 72 \\
\hline 4 & performance & 140 & 14 & level & 72 \\
\hline 5 & business & 138 & 15 & work & 71 \\
\hline
\end{tabular}


Table 2. Cont

\begin{tabular}{llllll}
\hline Position & Word & Frequency & Position & Word & Frequency \\
\hline 6 & risk & 119 & 16 & strategy & 70 \\
\hline 7 & management & 116 & 17 & emissions & 69 \\
\hline 8 & growth & 110 & 18 & revenue & 68 \\
\hline 9 & market & 107 & 19 & impact & 66 \\
\hline 10 & financial & 102 & 20 & carbon & 65 \\
\hline Total non-stop words 3905 & & & \\
\hline $\begin{array}{l}\text { Mean }=5 \text {; St. deviation }=11 ; \text { Median = 2; Median deviation }=1 \text {; Skewness = 11; Quartiles }= \\
\{1,2,5\} ; \text { Deciles }=\{1,1,1,1,2,3,4,6,11\} ; \text { Frequency upper 1\% quantile }=43 .\end{array}$ \\
\hline
\end{tabular}

Table 3. Bigrams frequency in the Strategy Report.

\begin{tabular}{|c|c|c|}
\hline Position & Bigram & Frequency \\
\hline 1 & $\{$ "international", "accounts" $\}$ & 34 \\
\hline 2 & $\{$ “management", "committee"\} & 31 \\
\hline 3 & $\{$ "executive", "officer"\} & 26 \\
\hline 4 & $\{$ “chief", “executive”\} & 26 \\
\hline 5 & $\{$ “fuel", "efficiency"\} & 23 \\
\hline 6 & $\{$ "customer", "experience" $\}$ & 23 \\
\hline 7 & $\{$ “financial”, "performance" $\}$ & 23 \\
\hline 8 & $\{$ “risk", "management”\} & 23 \\
\hline 9 & $\{$ “operations", “profit”\} & 22 \\
\hline 10 & $\{$ “customer", “load”\} & 19 \\
\hline 11 & $\{$ "load", "factor" $\}$ & 17 \\
\hline 12 & $\{$ “operations", "margin”\} & 16 \\
\hline 13 & $\{$ "traffic", "control" $\}$ & 16 \\
\hline 14 & \{"financial", "statements" $\}$ & 16 \\
\hline 15 & $\{$ "customer", "revenue" $\}$ & 15 \\
\hline 20 & $\{$ “non-fuel", “cost" $\}$ & 14 \\
\hline 22 & $\{$ "climate", "change" $\}$ & 12 \\
\hline
\end{tabular}

Table 4. Trigrams frequency in the Strategy Report.

\begin{tabular}{|c|c|c|}
\hline Position & Trigram & Frequency \\
\hline 1 & \{“chief", “executive”, “officer”\} & 26 \\
\hline 3 & \{"adjusted", “operations", "margin”\} & 13 \\
\hline 8 & \{“aspect”, “link”, “SDG”\} & 8 \\
\hline 11 & \{“return”, “invested”, “capital”\} & 8 \\
\hline 13 & \{“SDG", "performance”, “indicator”\} & 7 \\
\hline 14 & $\{$ “link”, “SDG”, “performance”\} & 7 \\
\hline 17 & \{"global", “leadership", "positions"\} & 7 \\
\hline 21 & $\{$ "risk", “context", "management" $\}$ & 6 \\
\hline 25 & \{"gender", "pay", "gap"\} & 5 \\
\hline
\end{tabular}




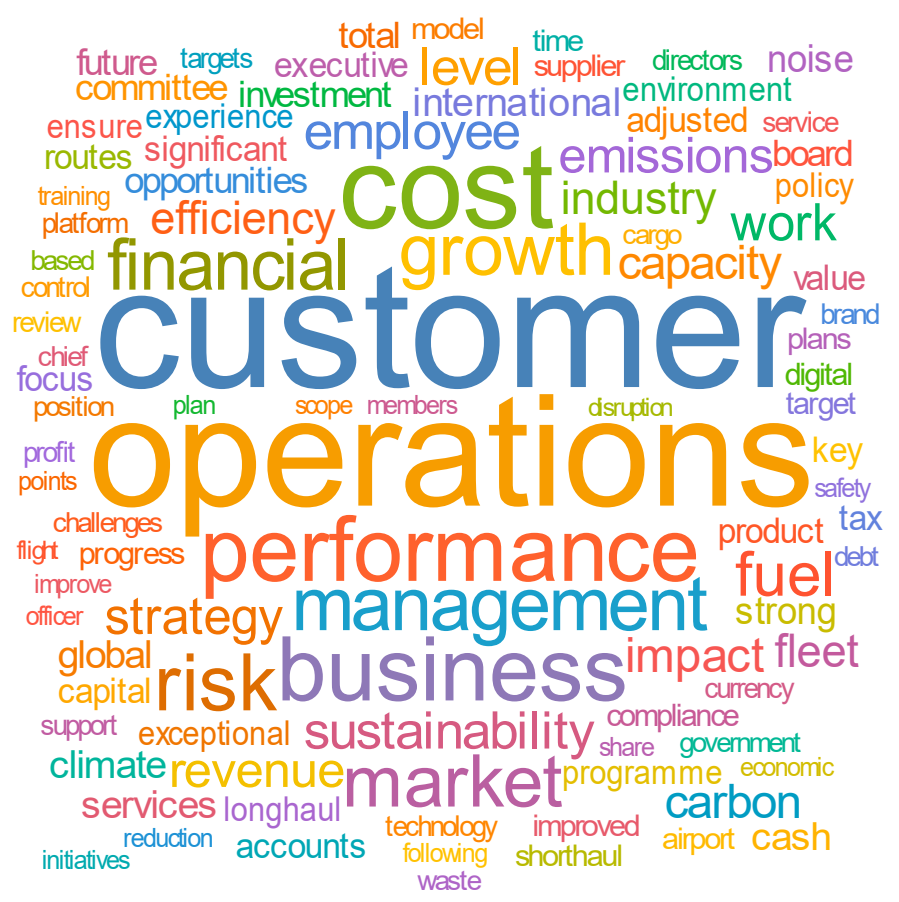

Figure 3. Strategy Report word cloud.

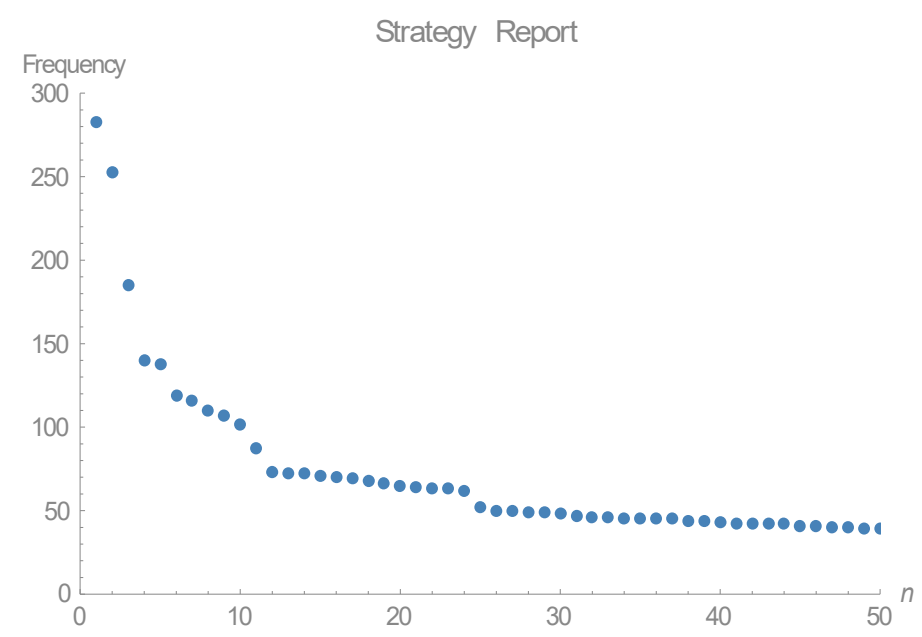

Figure 4. Frequency table plot (Strategy Report).

Centring on the sustainability report, not surprisingly, the word "sustainability" turns out to be the most frequent. Table 5 displays the frequencies of the words in this report, while Table 6 displays its bigrams. Figures 5 and 6 present the corresponding word cloud and frequencies table. The high positions of the words "aircraft", "operations", "emissions", and "carbon" convey the corporate interest on environmental sustainability, centrally focused on carbon emissions. The analysis of the bigrams-where "fuel efficiency" appears in the 1st position, followed by "operations, company" and "sustainability fuels", while "climate change" occupies the 5th position-confirms this view. The equally relevant positions (15th and 16th) of "CO emissions" and "low carbon" reinforce it. 
Table 5. Word frequency in the Sustainability Report.

\begin{tabular}{llllll}
\hline Position & Word & Frequency & Position & Word & Frequency \\
\hline 1 & sustainability & 96 & 11 & customer & 35 \\
\hline 2 & employee & 72 & 12 & performance & 35 \\
\hline 3 & aircraft & 65 & 13 & efficiency & 33 \\
\hline 4 & operations & 62 & 14 & management & 32 \\
\hline 5 & emissions & 57 & 15 & business & 29 \\
\hline 6 & carbon & 54 & 16 & waste & 29 \\
\hline 7 & airline & 48 & 17 & report & 27 \\
\hline 8 & noise & 45 & 18 & based & 27 \\
\hline 9 & climate & 43 & 19 & data & 27 \\
\hline 10 & fuel & 41 & 20 & compliance & 27 \\
\hline Total non-stop words 1981 & \multicolumn{5}{l}{} \\
\hline $\begin{array}{l}\text { Mean }=3.31 ; \text { St. deviation }=5.69 ; \text { Median }=2 ; \text { Median deviation }=1 ; \text { Skewness }=7 ; \text { Quartiles }= \\
\{1,2,3\} ; \text { Deciles }=\{1,1,1,1,2,2,3,4,\} ; \text { Frequency upper } 1 \% \text { quantile }=27 .\end{array}$ \\
\hline
\end{tabular}

Table 6. Bigrams frequency in the Sustainability Report.

\begin{tabular}{|c|c|c|}
\hline Position & Bigram & Frequency \\
\hline 1 & $\{$ "fuel", "efficiency"\} & 20 \\
\hline 2 & \{“operations", “company"\} & 16 \\
\hline 3 & \{"sustainability", "fuels"\} & 15 \\
\hline 5 & $\{$ "climate", "change" $\}$ & 11 \\
\hline 6 & $\{$ "management", "committee" $\}$ & 11 \\
\hline 7 & \{"airline", "report"\} & 10 \\
\hline 9 & \{“sustainability", "performance"\} & 10 \\
\hline 10 & \{“sustainability", "continued"\} & 10 \\
\hline 15 & $\left\{" \mathrm{co}^{\prime \prime}\right.$, "emissions" $\}$ & 9 \\
\hline 16 & $\{$ 'low", "carbon" $\}$ & 9 \\
\hline 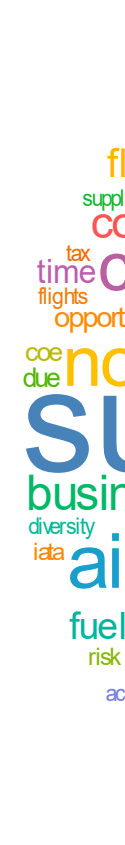 & 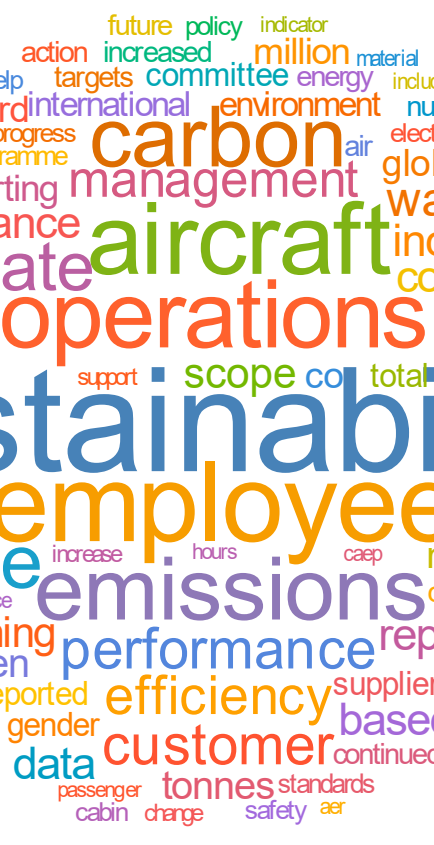 & $\begin{array}{l}\text { port } \\
\text { work } \\
\text { nglevel } \\
\text { miny icao } \\
\text { ustry men } \\
\text { ustry age }\end{array}$ \\
\hline
\end{tabular}

Figure 5. Sustainability Report word cloud. 


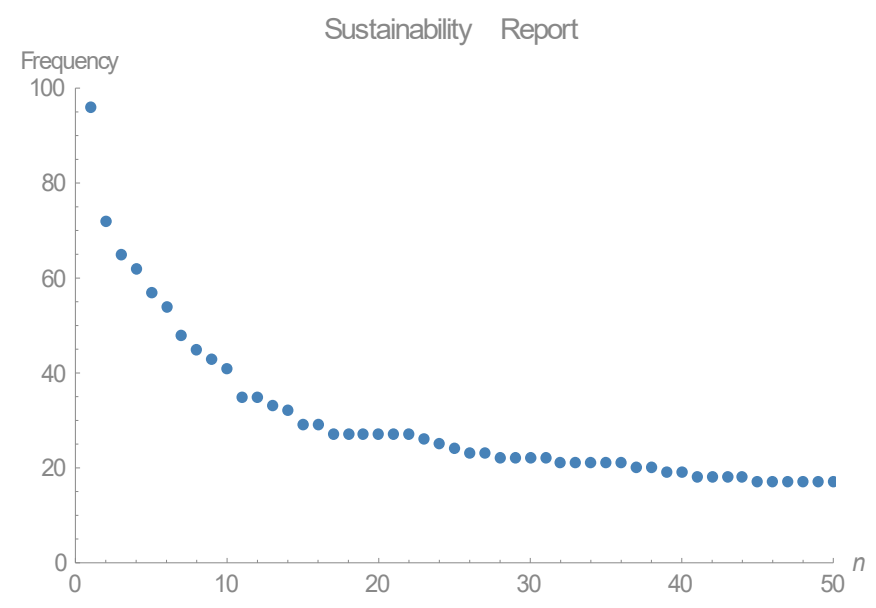

Figure 6. Frequency table plot (Sustainability Report.)

The corporate capital budgeting analysis is not disclosed due to its confidentiality. However, the whole report and its text analysis present enough evidence of the existence and application of the capital budgeting circle closely connected with corporate strategic planning.

The conjoint interpretation of any text analysis lies in its capacity for identifying the keywords of the text through the frequencies of single words. The word associations in bigrams and trigrams enhances its potential. The scientific legitimacy of text analysis is justified by the methodological works on the subject; some of them have been quoted above. Interpreting the results of the text analysis in the full context of the documents under study is a central requirement. In the case of IAG's strategic and sustainability reports, the text analysis identifies corporate externalities as relevant keywords. The term "sustainability" also has the value of a principal keyword. Terms related to corporate performance and business context are categorised as main keywords as well, especially in the strategic report. By itself, this text analysis does not show the corporate attitude towards externalities and sustainability, although, considering the general social and economic concern on sustainability, we could hardly expect keywords to be associated to a negationist attitude towards sustainability. The IAG's sustainability strategy has been identified through the conceptual analysis of its reports presented in the first paragraphs of this case study. To sum up, the frequency analysis has confirmed that the corporate investment projects mentioned in the sustainability report as the central courses of action for dealing with corporate externalities belong to a text in which these externalities appear as keywords.

All in all, the questions asked at the beginning of this case study receive positive answers. The CSR of IAG is focused on the mitigation of its externalities, mainly carbon emissions and noise. To achieve this goal, IAG undertakes investment projects with a long-run horizon by renewing its fleet, investing in new software, and supporting innovation. The dialogue with stakeholders is also well argued for in the report as the value creation for stakeholders through specific programmes. The financial sustainability of the CSR policy-and, thus, the value creation for shareholders-is inherent to the repeatedly stated goal of creating sustainable value, namely value for the long run. The CSR investment projects of IAG confirm this statement. The compatibility between this setting and the capital budgeting model developed in this paper is justified by the mitigation of externalities as the central CSR goal, and by assuming the goals of efficacy for the natural and social capitals together with economic efficiency for stakeholders and value creation for shareholders in the CSR investment projects undertaken by IAG for mitigating its main externalities. Table 7 summarises the questions and answers of the IAG case study.

The conceptual map presented in Figure 7 summarises the contents of this paper. It expresses the process that connects the corporate investment projects with the CSR strategy when CSR focuses on the control of the negative externalities produced by corporate investments. After a scenario analysis and a dialogue with stakeholders and employees, the corporation designs a CSR project aimed at mitigating the negative externalities. The analysis of this project consists of evaluating its capacity for controlling the externalities under consideration (efficacy), its economic efficiency for stakeholders, 
and its impact on corporate value, i.e., its financial sustainability for shareholders. The outcome of this analysis constitutes the CSR vector for the project under analysis. The indicators of the CSR vector can be summarised in a single metric, as shown in this paper.

Table 7. Questions and answers of the IAG case study.

\begin{tabular}{|c|c|}
\hline Questions & Answers \\
\hline $\begin{array}{l}\text { Is the CSR policy of IAG focused on mitigating the } \\
\text { externalities generated by its mainstream activity? }\end{array}$ & $\begin{array}{l}\text { CSR focused on the mitigation of carbon emissions and on } \\
\text { noise reduction. }\end{array}$ \\
\hline $\begin{array}{l}\text { Does the corporation undertake investment projects } \\
\text { for their mitigation? }\end{array}$ & $\begin{array}{l}\text { Yes. Mainly fleet renewal, new software for fuel } \\
\text { management, and support to innovation and research. }\end{array}$ \\
\hline $\begin{array}{c}\text { Does the corporation dialogue with stakeholders on } \\
\text { sustainability issues? }\end{array}$ & $\begin{array}{l}\text { Shared initiatives with partners, associations, governments, } \\
\text { and other stakeholders for improving sustainability.Talks } \\
\text { with communities living near the airports (noise reduction). }\end{array}$ \\
\hline $\begin{array}{l}\text { Does the corporation aim to create value for } \\
\text { its stakeholders? }\end{array}$ & $\begin{array}{l}\text { Support programmes for employees (including gender } \\
\text { equality) and external programmes for society } \\
\text { (including scholarships). }\end{array}$ \\
\hline $\begin{array}{l}\text { Is its CSR policy also oriented to creating value for } \\
\text { its shareholders? }\end{array}$ & IAG assumes the goal of creating sustainable value. \\
\hline
\end{tabular}

GRAPHICAL ABSTRACT

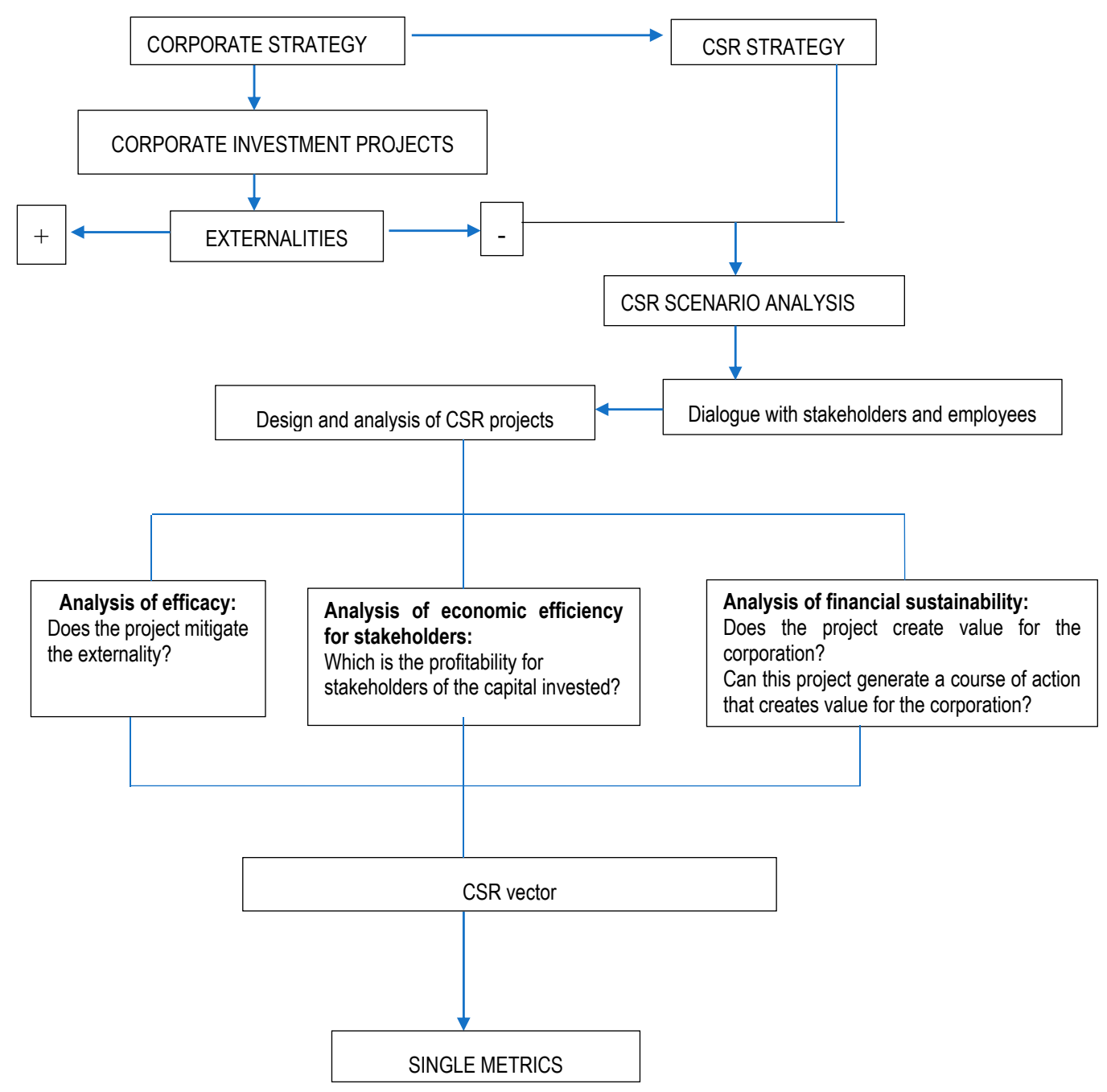

Figure 7. Graphical abstract. 
The conceptual map presented in Figure 7 summarises the contents of this paper. It expresses the process that connects the corporate investment projects with the CSR strategy when CSR focuses on the control of the negative externalities produced by corporate investments. After a scenario analysis and a dialogue with stakeholders and employees, the corporation designs a CSR project aimed at mitigating the negative externalities. The analysis of this project consists of evaluating its capacity for controlling the externalities under consideration (efficacy), its economic efficiency for stakeholders, and its impact on corporate value, i.e., its financial sustainability for shareholders. The outcome of this analysis constitutes the CSR vector for the project under analysis. The indicators of the CSR vector can be summarised in a single metrics, as shown in this paper.

\section{Discussion and Conclusions}

This paper has departed from the mitigation of negative corporate externalities through CSR projects. A complete evaluation of CSR projects requires extending the traditional capital budgeting, focused on financial capital, to natural and social capitals. This paper has aimed to obtain a coherent set of rules for the evaluation of CSR projects. The capital budgeting of CSR sets up a twofold challenge: what to measure and how to measure it. The scope of its measurement embraces the technical efficacy for mitigating the externalities which it focuses on, the economic efficiency for stakeholders, and the financial sustainability for shareholders. These multifaceted requirements force the analyst to deal with natural units for the effects on natural and social capitals, and with monetary units for the financial impacts on stakeholders and shareholders. Regarding stakeholders, they are at the same time recipients of the mitigation of externalities, measured in natural units, and of the monetary effect of this mitigation on their financial position. Namely, CSR projects impact their social welfare (natural units) and their economic welfare (monetary units). This paper has approached the measurement of these diverse, but related, impacts through the metrics summarised in the CSR vector. This vector expresses the impact of the project through two efficacy rates and two value creation rates. The efficacy rates refer to the natural and social capitals, while the value creation rates are estimated from the points of view of stakeholders and shareholders. The estimation of the financial value creation rates is the outcome of transforming the SROI, for stakeholders, and the PVI, for shareholders, into continuous rates that express the change of the capital invested into the value created from both perspectives, namely for stakeholders and shareholders. By incorporating the efficacy and the value creation rates, the CSR vector summarises the main contributions of CSR projects to environmental, social, and financial sustainability. The four rates of this vector can be reduced to a single metric, the overall profitability rate, which expresses their conjoint effect through a unique numerical figure. Different values of this figure can be obtained by weighting the four rates of the CSR vector with appropriate criteria. The information provided by the CSR vector and the overall profitability rate enables managers to improve their decisions on CSR courses of action.

The broader context of CSR projects concerning ordinary projects broadens, as well, the goals and the complexity of capital budgeting. The goal of traditional capital budgeting is the measurement of the financial value creation generated by investment projects. From this perspective, value creation consists of the growth of the corporate financial capital according to the financial market's criteria. Extending financial capital budgeting to the natural and social capitals means to measure the improvement in both capitals generated by the project under analysis. Different metrics, mentioned in this paper, have been developed for encapsulating in a single indicator the different impacts of an environmental course of action. The same holds for social courses of action. The capital budgeting of CSR projects requires the measurement of four impacts: the environmental efficacy (efficacy for the natural capital), the social efficacy (efficacy for the social capital), the economic efficiency for the stakeholders, and the economic efficiency for shareholders, i.e., the financial value creation in the latter case.

In addition to the strict topic of capital budgeting, this paper has also considered the links between capital budgeting and strategic planning for CSR projects. Beyond the well-known relationships between capital budgeting and strategic planning, the CSR's point of view leads to the incorporation of 
the corporate dialogue between corporate managers and stakeholders and the links between CSR and corporate strategy. Centring the analysis of CSR goals on the mitigation of the negative externalities generated by corporate activity strengthens the synergy between CSR and sustainability, bringing CSR actions in line with the SDGs. Finally, this approach reduces the corporate regulatory risk because it advances the mitigation of negative corporate externalities before regulators make it compulsory. In brief, this paper has argued, following core literature on CSR, that corporations should set up a CSR strategy as part of their general strategy. Identifying the negative externalities generated by the corporation through a cost-benefit analysis provides an objective set of possible and desirable CSR courses of action, which can often be studied as investment projects. The coherence of any CSR investment project with the CSR strategic planning is compulsory for its feasibility. Beyond that, its final acceptance depends on the results of its capital budgeting analysis from the triple point of view of the natural, social, and financial capitals.

The conceptual map displayed in Figure 7 stresses the contributions of this paper, from the design of CSR projects to their evaluation for the natural, social, and financial capitals. In the approach of this paper, the design of CSR projects departs from assuming the goal of mitigating the externalities generated by mainstream projects. At this stage, the challenge is the identification of plausible courses of action that lead to this goal. Identifying plausible projects requires a scenario analysis centred on the possible evolution of externalities and on the study of which corporate skills can actively control them. A productive dialogue with stakeholders and employees has a high potential for becoming a source of central pieces of information in the design of CSR projects. Plausible projects are then evaluated to determine their capacity for value creation. However, approaching value creation from CSR requires estimating the projects' contribution to the natural, social, and financial capitals. Besides, their financial impacts must be evaluated from the points of view of stakeholders and shareholders. The capital budgeting method developed in this paper summarises, in the CSR vector reports, the contributions of the project under analysis to the natural and social capitals, its economic efficiency for stakeholders, and its financial sustainability for shareholders. The single measure in which these four outcomes can be synthesized may attribute different weights to each contribution, but the analysis of these weights is left for further research. A case study grounded in text-mining techniques has highlighted the interest of this approach.

To conclude, we summarise the goal and the findings of this paper. Its goal has been to build up a capital budgeting model able to assess the different outcomes of CSR projects aimed at mitigating corporate externalities. We have concluded that these outcomes are the technical efficacy for the natural and social capitals, the economic efficiency for stakeholders, and the financial sustainability for shareholders. The need for integrating CSR projects into corporate strategy has also been shown. The findings have consisted of: analysing the particular features of CSR strategic planning; identifying existing, although independent indicators for efficacy, efficiency, and financial sustainability; turning the chosen indicators into value creation rates that may receive a homogeneous interpretation; integrating these rates into the CSR vector as the central set of indicators for the evaluation of CSR projects; and building a single metric by combining these indicators. These contributions open new paths for further research.

Author Contributions: Conceptualization, M.-T.B.-B., J.M.-S., and M.-A.T.-R.; methodology, M.-T.B.-B., J.M.-S., and M.-A.T.-R.; software, M.-T.B.-B., J.M.-S., and M.-A.T.-R.; validation, M.-T.B.-B., J.M.-S., and M.-A.T.-R.; formal analysis, M.-T.B.-B., J.M.-S., and M.-A.T.-R.; investigation, M.-T.B.-B., J.M.-S., and M.-A.T.-R.; resources, M.-T.B.-B., J.M.-S., and M.-A.T.-R.; data curation, M.-T.B.-B., J.M.-S., and M.-A.T.-R.; writing—original draft preparation, M.-T.B.-B., J.M.-S., and M.-A.T.-R.; writing—review and editing, M.-T.B.-B., J.M.-S., and M.-A.T.-R.; visualization, M.-T.B.-B., J.M.-S., and M.-A.T.-R.; supervision, M.-T.B.-B., J.M.-S., and M.-A.T.-R. All authors have read and agreed to the published version of the manuscript.

Funding: This research received no external funding.

Acknowledgments: The authors thank four anonymous reviewers for their valuable comments. The usual disclaimer applies.

Conflicts of Interest: The authors declare no conflict of interest 


\section{Appendix A}

This appendix presents the technical development of some of the results obtained or mentioned in Section 5 (Metrics). It starts with the development of the efficacy ratios in a multiperiod setting, continues by considering a slightly different interpretation of the profitability index, and ends with the detailed obtention of the single metric for CSR projects, departing from Sikdar's approach.

\section{The efficacy ratios in a multiperiod setting.}

The expected impact of the CSR project on the externality indicator can be constant or may present different values during the development of the project. In this second case, the evolution of the externalities indicator is represented by the vector:

$$
\left\{\varepsilon_{0}, \varepsilon_{1} \ldots \varepsilon_{t} \ldots \varepsilon_{n}\right\}
$$

where $n$ denotes the life of the CSR project.

Then, the efficacy ratio of year $t$ turns out to be:

$$
\gamma_{t}=\frac{\varepsilon_{t-1}}{\varepsilon_{t}}
$$

The value of the efficacy ratio can be summarised by its geometric mean:

$$
\gamma^{*}=\left(\gamma_{1} \cdot \gamma_{2} \cdot \ldots \gamma_{t} \cdot \ldots \gamma_{n}\right)^{\frac{1}{n}}=\left(\frac{\varepsilon_{0}}{\varepsilon_{n}}\right)^{\frac{1}{n}}
$$

The ratio between $\varepsilon_{0}$ and $\varepsilon_{n}$ expresses the continuous capitalisation of the average efficacy rate $\left(\omega^{*}\right)$ during $n$ periods $\left(e^{\omega^{*} n}\right)$. Substituting $\left(\varepsilon_{0} / \varepsilon_{n}\right)$ by $e^{\omega^{*} n}$ in Equation (A3), after simplifying and solving $\omega^{*}$, the average efficacy rate, becomes:

$$
\omega^{*}=\ln \gamma^{*}
$$

which shows that the efficacy rate of natural capital increases with the efficacy ratio. The efficacy rate is straightforwardly interpreted by realising that it consists in the continuous rate at which the initial value of the environmental indicator has decreased until reaching its final value:

$$
\varepsilon_{0} e^{-\omega^{*} n}=\varepsilon_{n}
$$

\section{The profitability index and the financial value creation rate.}

As stated in Equation (8), the most common version of the profitability index consists of assimilating it to the ratio between the gross present value and the present value (GPV) of the capital invested (PVC). However, Herbst [61] (p. 51) prefers substituting the GPV with the NPV in the numerator of this ratio, writing the profitability index as:

$$
p=\frac{N P V}{P V C}=\frac{G P V-P V C}{P V C}
$$

Thus, in Herbst's version, the profitability index $(p)$ becomes a rate of return that enlightens the connection between the profitability index and the financial value creation rate presented in Equation (9). In effect, after Equation (A6) the traditional version of the profitability index can be related to Herbst's as:

$$
1+p=\frac{G P V}{P V C}
$$


And, expressing $p$ as a continuous rate, we obtain the financial value creation rate presented in Equation (9). Hence:

$$
f=\ln P V I
$$

\section{Building up a single metric.}

The four indicators of the CSR vector can be united in a single metric, following the work by Sikdar [32,33]. The aggregate metric that we introduce is an adaptation of Sikdar [32], who proposes the weighted geometric mean for comparing two states of a system: $S_{1}\left(x_{1}, x_{2}, \ldots, x_{n}\right)$ and $S_{2}\left(y_{1}, y_{2}, \ldots, y_{n}\right)$. Sikdar's formula is [32] (p. 158):

$$
D=\left(\prod_{i}^{n}\left[c_{i}\left(\frac{y_{i}}{x_{i}}\right)\right]\right)^{\frac{1}{n}}
$$

where $D$ stands for "distance", meaning the aggregate improvement in sustainability generated by the set on indicators incorporated into Equation (A9). Weights are denoted by $c$. For the sake of clarity, we will henceforth use the term "metric" to denote the aggregated measure $(D)$ and the term "indicator" to denote the specific measures $(x, y)$ that the aggregated metric unites. When, in literal quotations, the term metric refers to specific measures, we add in parenthesis the term "indicator" in inverted commas.

Referring to the negative externalities impacting the natural capital, Sikdar points out that "care needs to be taken to ensure that the metrics ("indicators") are defined in such a way that a decrease in the value of any metrics ("indicator") signifies an improvement" [32] (p. 158). Apparently, this requirement is a barrier for combining the efficacy of the natural capital with the social efficacy and financial indicators in the aggregated metric. The goal of Sikdar's condition is to exclude contradictory interpretations in the different indicators integrated into the metric. A homogeneous interpretation of the evolution of the indicators can also be achieved by defining all of them in such a way that increases systematically express improvement and decreases deterioration, as in the case of social and financial capitals indicators. The efficacy ratio of the natural capital defined in Equation (1) is coherent with this interpretation because it compares the initial value of the indicator (numerator) with its final value (denominator). Let us point out that Sikdar's metric is focused on the natural capital, while this paper proposes to extend it to the social and financial capitals.

A second condition for the applicability of this metric is that indicators cannot be zero [32] (p. 158) or negative [33] (p. 766). In the metric presented in this paper, a zero or negative expected value of an indicator is a sufficient condition to discard the project; thus, there is no point in applying the aggregate metrics in these cases. An inverse efficacy ratio equal to zero can only take place if the value of the externality is nil, in which case there will not be any negative externality to consider. A zero or negative SROI is an obvious sufficient condition to reject the project. As for the profitability index, a zero value denotes that the capital invested in the project will be wholly lost, even considering its non-cash contributions to the corporate value. Therefore, we have a sufficient condition for discarding the project again. Sikdar et al. [33] (p. 766) also present a transformation to make all indicators greater than zero.

The two states that our indicators compare are the scenarios before and after the CSR investment project. The CSR vector (10) consists of ratios that express the changes generated by the CSR project. For the efficacy indicators of the natural and social capitals $(\gamma$ and $\varsigma)$, this statement is obvious. As for SROI and PVI, they compare the gross value created by the capital invested for stakeholders (SPV) and shareholders (GPV) with the value of this capital before starting the CSR project (PVC). Therefore, they can be interpreted as indicators of the change generated by the CSR project in their respective areas, paralleling the efficacy ratios. On this basis, Sikdar's metrics can be directly applied to the CSR vector. Excluding weights in the geometric mean, its expression for the CSR vector becomes:

$$
D=\left(\gamma^{*} \cdot \varsigma^{*} \cdot S R O I^{*} \cdot P V I^{*}\right)^{\frac{1}{4}}
$$


Writing these ratios as a function of their corresponding change rates, we have:

$$
D=\left(e^{w^{*}} \cdot e^{\eta^{*}} \cdot e^{v} \cdot e^{f}\right)^{\frac{1}{4}}
$$

Recalling the relationships between these ratios and their corresponding continuous rates of efficacy and return, the natural logarithm of $D$ consists of the arithmetic average of the efficacy rates of natural and social capitals and the value creation rates for stakeholders and shareholders:

$$
\ln D=\frac{1}{4} \omega^{*}+\frac{1}{4} \eta^{*}+\frac{1}{4} v+\frac{1}{4} f
$$

Since $\ln D$ is a monotonously increasing function of $D$, the arithmetic average of the four rates of returns can be accepted as a single metric for integrating efficacy, efficiency, and financial value creation in a single indicator.

The aggregate metric $D$, defined in this way, can be conceived as an index of overall profitability that encapsulates socio-environmental efficacy, economic efficiency, and financial sustainability. At the inception of the project, its value is normalised at 1 . Thus, the rate of return of the index $(\mu)$, which we will call overall profitability rate, is:

$$
e^{\mu}=D
$$

Thus, from Equation (A12) we have:

$$
\mu=\frac{1}{4} \omega^{*}+\frac{1}{4} \eta^{*}+\frac{1}{4} v+\frac{1}{4} f
$$

The four rates that integrate the overall profitability rate can be weighted according to the importance that the decision-maker attributes to each one of them. These weights can be introduced in the geometric mean of the ratios, as in Sikdar's original formula Equation (A9), or directly in the overall profitability rate, i.e., in Equation (A14). The direct introduction in Equation (A14) facilitates the comparison between different weighting criteria. After introducing the weights, Equation (A14) becomes Equation (12):

$$
\mu=w_{\omega} \omega+w_{\eta} \eta+w_{v} v+w_{f} f
$$

where, to simplify notations, $\omega$ and $\eta$ stand indistinctively for one period or geometric average rates (i.e., $\omega^{*}$ and $\eta^{*}$ in Equation (A14)), because the only purpose of this distinction is to evolve from the one period to the multihorizon setting, but without any conceptual change.

\section{References}

1. Sheehy, B. Defining CSR: Problems and Solutions. J. Bus. Ethics 2015, 131, 625-648. [CrossRef]

2. Boardman, A.E. Usando el Analisis de Costo-Beneficio Social para Medir la Responsabilidad Social Corporativa. Infogas 2009, 5, 7-14.

3. Boardman, A.E.; Greenberg, D.H.; Vining, A.R.; Weimer, D.L. Cost-Benefit Analysis, 5th ed.; Cambridge University Press: Cambridge, UK, 2018.

4. Jenkins, G.P.; Kuo, C.Y.; Harberger, A.C. Cost-Benefit Analysis for Investment Decisions, 1st ed.; Cambridge Resources International: Cambridge, UK, 2018.

5. KPMG International. A New Vision of Value; 2014; Available online: https://home.kpmg/xx/en/home/insights/ 2014/09/a-new-vision-connecting-corporate.html (accessed on 10 November 2019).

6. Porter, M.E.; Serafeim, G.; Kramer, M.R. Where ESG Fails. Available online: https://sharedvalue.org.au/wpcontent/uploads/2019/11/Where-ESG-Fails-_-Institutional-Investor.pdf (accessed on 16 October 2019).

7. Székely, F.; Knirsch, M. Responsible Leadership and Corporate Social Responsibility. Eur. Manag. J. 2005, 23, 628-647. [CrossRef]

8. Singh, R.K.; Murty, H.R.; Gupta, S.K.; Dikshit, A.K. An Overview of Sustainability Assessment Methodologies. Ecol. Indic. 2012, 15, 281-299. [CrossRef] 
9. Angelakoglou, K.; Gaidajis, G. A Review of Methods Contributing to the Assessment of the Environmental Sustainability of Industrial Systems. J. Clean. Prod. 2015, 108, 725-747. [CrossRef]

10. Singh, R.K.; Murty, H.R.; Gupta, S.K.; Dikshit, A.K. Development of Composite Sustainability Performance Index for Steel Industry. Ecol. Indic. 2007, 7, 565-588. [CrossRef]

11. Naidu, S.; Sawhney, R.; Li, X. A Methodology for Evaluation and Selection of Nanoparticle Manufacturing Processes Based on Sustainability Metrics. Environ. Sci. Technol. 2008, 42, 6697-6702. [CrossRef]

12. Ellison, L.; Brown, P. Sustainability Metrics for Commercial Real Estate Assets-Establishing a Common Approach. J. Eur. Real Estate Res. 2011, 4, 113-130. [CrossRef]

13. Kouadio, L.; Newlands, N.K. Building Capacity for Assessing Spatial-Based Sustainability Metrics in Agriculture. Decis. Anal. 2015, 2, 2. [CrossRef]

14. Bhattacharyya, A.; Cummings, L. Measuring Corporate Environmental Performance-Stakeholder Engagement Evaluation. Bus. Strategy Environ. 2013, 24, 309-325. [CrossRef]

15. Mitnick, B.M. Commitment, Revelation, and the Testaments of Belief: The Metrics of Measurement of Corporate Social Performance. Bus. Soc. 2000, 39, 419-465. [CrossRef]

16. Salazar, J.; Husted, B.W.; Biehl, M. Thoughts on the Evaluation of Corporate Social Performance Through Projects. J. Bus. Ethics 2011, 105, 175-186. [CrossRef]

17. Wood, D.J. Measuring Corporate Social Performance: A Review. Int. J. Manag. Rev. 2010, 12, 50-84. [CrossRef]

18. U.N. Guiding Principles on Business and Human Rights. Available online: https://www.ohchr.org/ Documents/Publications/GuidingPrinciplesBusinessHR_EN.pdf (accessed on 25 October 2019).

19. ISO. Guidance on Social Responsibility. Available online: https://iso26000.info/related-standards/ (accessed on 30 September 2019).

20. Chandler, D. Strategic Corporate Social Responsibility, 5th ed.; Sage Publications: London, UK, 2020.

21. Emerson, J.; Wachowicz, J.; Chun, Z. Social Return on Investment: Exploring Aspects of Value Creation in the Nonprofit Sector. Available online: https://redf.org/wp-content/uploads/REDF-Box-Set-Vol.-2-SROIPaper-2000.pdf (accessed on 2 October 2019).

22. Lingane, A.; Olsen, S. Guidelines for Social Return on Investment. Calif. Manag. Rev. 2004, 46, 116-135. [CrossRef]

23. Sones, M.; Grantham, S.; Vieira, E.T. Communicating CSR via pharmaceutical company web sites. Corp. Commun. 2009, 14, 144-157. [CrossRef]

24. Maas, K.; Liket, K. Talk the Walk: Measuring the Impact of Strategic Philanthropy. J. Bus. Ethics 2010, 100, 445-464. [CrossRef]

25. Lombardo, G.; Mazzocchetti, A.; Rapallo, I.; Tayser, N.; Cincotti, S. Assessment of the Economic and Social Impact Using SROI: An Application to Sport Companies. Sustainability 2019, 11, 3612. [CrossRef]

26. Maier, F.; Schober, C.; Simsa, R.; Millner, R. SROI as a Method for Evaluation Research: Understanding Merits and Limitations. Voluntas 2014, 26, 1805-1830. [CrossRef]

27. Nicholls, J.; Lawlor, E.; Neizert, E.; Goodspeed, T. A Guide to Social Return on Investment. Available online: http://www.socialvalueuk.org/app/uploads/2016/03/The\%20Guide\%20to\%20Social\%20Return\% 20on\%20Investment\%202015.pdf (accessed on 5 October 2019).

28. Nicholls, A.; Patton, R. Projection, Valuation, and Pricing in Social Finance. In Social Finance; Nicholls, A., Patton, R., Emerson, J., Eds.; Oxford University Press: Oxford, UK, 2015; pp. 311-334. [CrossRef]

29. Pattison-Williams, J.K.; Pomeroy, J.W.; Badiou, P.; Gabor, S. Wetlands, Flood Control and Ecosystem Services in the Smith Creek Drainage Basin: A Case Study in Saskatchewan, Canada. Ecol. Econ. 2018, 147, 36-47. [CrossRef]

30. Secco, L.; Pisani, E.; Da Re, R.; Rogelja, T.; Burlando, C.; Vicentini, K.; Pettenella, D.; Masiero, M.; Miller, D.; Nijnjk, M. Towards a method of evaluating social innovation in forest-dependent rural communities: First suggestions from a science-stakeholder collaboration. For. Policy Econ. 2019, 104, 9-22. [CrossRef]

31. Bottero, M.; Comino, E.; Dell'Anna, F.; Dominici, L.; Rosso, M. Strategic Assessment and Economic Evaluation: The Case Study of Yanzhou Island (China). Sustainability 2019, 11, 1076. [CrossRef]

32. Sikdar, S.K. On Aggregating Multiple Indicators into a Single Metric for Sustainability. Clean Technol. Environ. Policy 2009, 11, 157-161. [CrossRef]

33. Sikdar, S.K.; Sengupta, D.; Harten, P. More on Aggregating Multiple Indicators into a Single Index for Sustainability Analyses. Clean Technol. Environ. Policy 2012, 14, 765-773. [CrossRef] 
34. Brandi, H.S.; Daroda, R.J.; Olinto, A.C. The use of the Canberra metrics to aggregate metrics to sustainability. Clean Technol. Environ. Policy 2013, 16, 911-920. [CrossRef]

35. El-Halwagi, M.M. A Return on Investment Metric for Incorporating Sustainability in Process Integration and Improvement Projects. Clean Technol. Environ. Policy 2017, 19, 611-617. [CrossRef]

36. Sikdar, S.; Sengupta, D.; Mukherjee, R. Measuring Progress Towards Sustainability; Springer: Cham, Switzerland, 2017.

37. West, J. Capital valuation and sustainability: A data programming approach. Rev. Quant. Financ. Account. 2014, 45, 591-608. [CrossRef]

38. Wilhelm, K. Return on Sustainability; Pearson Education: Upper Saddle River, NJ, USA, 2013.

39. Buffet, H.W.; Eimicke, W.B. Social Value Investing; Columbia University Press: New York, NY, USA, 2018.

40. Porter, M.E.; Kramer, M.R. Strategy \& Society: The Link Between Competitive Advantage and Corporate Social Responsibility. Harv. Bus. Rev. 2006, 12, 78-92.

41. Kim, K.-H.; Kim, M.; Qian, C. Effects of Corporate Social Responsibility on Corporate Financial Performance: A Competitive-Action Perspective. J. Manag. 2015, 44, 1097-1118. [CrossRef]

42. Lins, K.V.; Servaes, H.; Tamayo, A. Social Capital, Trust, and Firm Performance: The Value of Corporate Social Responsibility during the Financial Crisis. J. Financ. 2017, 72, 1785-1824. [CrossRef]

43. Wang, Q.; Dou, J.; Jia, S. A Meta-Analytic Review of Corporate Social Responsibility and Corporate Financial Performance. Bus. Soc. 2016, 55, 1083-1121. [CrossRef]

44. Orlitzky, M.; Schmidt, F.L.; Rynes, S.L. Corporate Social and Financial Performance: A Meta-Analysis. Organ. Stud. 2003, 24, 403-441. [CrossRef]

45. Myers, S.C. Finance Theory and Financial Strategy. Interfaces 1984, 14, 126-137. [CrossRef]

46. Rizzi, J.V. Capital Budgeting: Linking Financial Analysis to Corporate Strategy. J. Bus. Strategy 1984, 4, 81-84.

47. Brealey, R.; Myers, S.; Allen, F. Principles of Corporate Finance, 10th ed.; McGraw-Hill/Irwin: New York, NY, USA, 2011.

48. Lai, V.S.; Trigeorgis, L. The Strategic Capital Budgeting Process: A Review of Theories and Practices. In Real Options in Capital Investment: New Contributions; Trigeorgis, L., Ed.; Praeger Publishers: Santa Barbara, CA, USA, 1995; pp. 69-86.

49. Desouza, K.C. Intrapreneurship: Managing Ideas within Your Organization; University of Toronto Press: Toronto, ON, Canada, 2011.

50. Ciriello, R.F.; Richter, A.; Schwabe, G. Digital innovation. Bus. Inf. Syst. Eng. 2018, 60, 563-569. [CrossRef]

51. Schoemaker, P.J.H. Scenario Planning: A Tool for Strategic Thinking. Sloan Manag. Rev. 1995, 36, $25-40$.

52. Amram, M.; Kulatilaka, N. Disciplined Decisions. Harv. Bus. Rev. 1999, 77, 95-96.

53. Arvidson, M.; Lyon, F.; McKay, S.; Moro, D. Valuing the Social? The Nature and Controversies of Measuring Social Return on Investment (SROI). Volunt. Sect. Rev. 2013, 4, 3-18. [CrossRef]

54. Yates, B.T.; Marra, M. Social Return on Investment (SROI): Problems, Solutions ... and is SROI a Good Investment? Eval. Program Plan. 2017, 64, 136-144. [CrossRef]

55. Porter, M.E.; Kramer, M.R. Creating Shared Value. Harv. Bus. Rev. 2011, 89, 62-77.

56. Porter, M.E.; Kramer, M.R. The Competitive Advantage of Corporate Philanthropy. Harv. Bus. Rev. 2002, 80, 56-68.

57. Husted, B.W. Risk Management, Real Options, Corporate Social Responsibility. J. Bus. Ethics 2005, 60, 175-183. [CrossRef]

58. Cassimon, D.; Engelen, P.-J.; Van Liedekerke, L. When do Firms Invest in Corporate Social Responsibility? A Real Option Framework. J. Bus. Ethics 2015, 137, 15-29. [CrossRef]

59. Bosch-Badia, M.T.; Montllor-Serrats, J.; Tarrazon-Rodon, M.A. Corporate Social Responsibility: A Real Options Approach to the Challenge of Financial Sustainability. PLoS ONE 2015, 10, e0125972. [CrossRef] [PubMed]

60. Bierman, H.; Smidt, S. The Capital Budgeting Decision: Economic Analysis of Investment Projects; Routledge: Abingdon, UK, 2012.

61. Herbst, A.F. Capital Asset Investment: Strategy, Tactics and Tools; Wiley: New York, NY, USA, 2002.

62. Magni, C.A. The Internal Rate of Return Approach and the AIRR Paradigm: A Refutation and a Corroboration. Eng. Econ. 2013, 58, 73-111. [CrossRef]

63. Magni, C.A. Mathematical Analysis of Average Rates of Return and Investment Decisions: The Missing Link. Eng. Econ. 2014, 59, 175-206. [CrossRef] 
64. OECD. Eco-Innovation in Industry. Available online: http://dx.doi.org/10.1787/9789264077225-en (accessed on 25 September 2019).

65. Keeler, E.B.; Cretin, S. Discounting of Life-Saving and Other Nonmonetary Effects. Manag. Sci. 1983, 29, 300-306. [CrossRef]

66. Scrieciu, S.Ş.; Belton, V.; Chalabi, Z.; Mechler, R.; Puig, D. Advancing methodological thinking and practice for development-compatible climate policy planning. Mitig. Adapt. Strateg. Glob. Chang. 2014, 19, 261-288. [CrossRef]

67. Pathak, P.; Dattani, P. Social Return on Investment: Three Technical Challenges. Soc. Enterp. J. 2014, 10, 91-104. [CrossRef]

68. Stern, N. The Economics of Climate Change. Am. Econ. Rev. 2008, 98, 1-37. [CrossRef]

69. Nordhaus, W.D. A Review of the Stern Review on the Economics of Climate Change. J. Econ. Lit. 2007, 45, 686-702. [CrossRef]

70. Markandya, A. Natural capital and the rate of discount. In Mainstreaming Natural Capital and Ecosystem Services into Development Policy; Kumar, P., Ed.; Routledge: Abingdon, UK, 2019; pp. 256-284. Available online: http://dx.doi.org/10.4324/9781315531212-11 (accessed on 12 September 2019).

71. Markanday, A.; Galarraga, I.; Chiabai, A.; Sainz de Murieta, E.; Lliso, B.; Markandya, A. Determining discount rates for the evaluation of natural assets in land-use planning: An application of the Equivalency Principle. J. Clean. Prod. 2019, 230, 672-684. [CrossRef]

72. Marini, G.; Scaramozzino, P. Social time preference. J. Popul. Econ. 2000, 13, 639-645. [CrossRef]

73. International Airlines Group (IAG) Annual Report. Available online: https://www.iairgroup.com/en/ investors-and-shareholders/results-and-reports (accessed on 10 August 2019).

74. Archer, D. Does Frequency Really Matter? In What's in a Word-List? Archer, D., Ed.; Routledge: Abingdon, UK, 2016; pp. 1-16. [CrossRef]

75. Davies, M. Word Frequency in Context. In What's in a Word-List? Archer, D., Ed.; Routledge: Abingdon, UK, 2016; pp. 53-68. [CrossRef]

76. Ignatow, G.; Mihalcea, R. Text Mining: A Guidebook for the Social Sciences; SAGE Publications, Inc.: Thousand Oaks, CA, USA, 2017. [CrossRef]

77. Popping, R. Qualitative Decisions in Quantitative Text Analysis Research. Sociol. Methodol. 2012, 42, 88-90. [CrossRef]

78. Bholat, D.; Hansen, S.; Santos, P.; Schonhart-Bailey, C. Text Mining for Central Banks. 2015. Available online: https://www.bankofengland.co.uk/-/media/boe/files/ccbs/resources/text-mining-for-central-banks. pdf?la=en\&hash=C49C23BF808B13FAD5361D0D2516DA12646120A6 (accessed on 23 February 2017).

79. Turkel, W.J. Digital Research Methods with Mathematica, 2nd ed.; Available online: https://williamjturkel.net/ digital-research-methods-with-mathematica/ (accessed on 13 September 2019). 